\title{
An injectable heparin-conjugated hyaluronan scaffold for local delivery of transforming growth factor $\beta 1$ promotes successful chondrogenesis
}

\author{
Journal Article \\ Author(s): \\ Levinson, Clara; Lee, Mihyun; Applegate, Lee A.; Zenobi-Wong, Marcy (D) \\ Publication date: \\ 2019-11 \\ Permanent link: \\ https://doi.org/10.3929/ethz-b-000377534 \\ Rights / license: \\ Creative Commons Attribution-NonCommercial-NoDerivatives 4.0 International \\ Originally published in: \\ Acta Biomaterialia 99, https://doi.org/10.1016/j.actbio.2019.09.017

\section{Funding acknowledgement:} \\ 159783 - A Bio-inspired Cartilage Mimetic with Enhanced Chondrogenic and Anti-inflammatory Properties (SNF) \\ 143667 - Drug-induced expression of the chondrogenic phenotype using a nanofiber-reinforced cartilage mimetic (SNF)
}




\section{An injectable heparin-conjugated hyaluronan scaffold for local delivery of TGF- $\beta 1$ promotes successful chondrogenesis}

Clara Levinson ${ }^{1}$, Lee Ann Applegate ${ }^{2}$, Marcy Zenobi-Wong ${ }^{1 \S}$

${ }^{1}$ Tissue Engineering + Biofabrication, Swiss Federal Institute of Technology (ETH), Zürich, Switzerland

${ }^{2}$ Unit of Regenerative Therapy, Lausanne University Hospital of, Lausanne, Switzerland

${ }^{\S}$ Address for correspondence:

Prof. M. Zenobi-Wong

Tissue Engineering + Biofabrication Laboratory

ETH Zürich

Otto-Stern-Weg 7, HPL J22

8093 Zürich, Switzerland

zmarcy@ethz.ch

Phone: +41 446325089

Fax: +41446331194

\section{Abstract}

Cartilage lacks basic repair mechanisms and thus surgical interventions are necessary to treat lesions. Minimally-invasive arthroscopic procedures require the development of injectable biomaterials to support chondrogenesis of implanted cells. However, most cartilage tissue engineering approaches rely on pre-culture of scaffolds in media containing growth factors (GFs) such as TGF- $\beta 1$, which are crucial for cartilage formation and homeostasis. GFs mediasupplementation is incompatible with injectable approaches and led to a knowledge gap about GFs optimal dose and release profile to achieve chondrogenesis. This study aims to determine the initial amount and release kinetics of TGF- $\beta 1$ bound in an engineered GAG hydrogel, to promote cartilaginous matrix production in absence of TGF- $\beta 1$ media-supplementation. We show that heparin, a GAG known to bind a wide range of GFs, covalently conjugated to a hyaluronan hydrogel, leads to a sustained release of TGF- $\beta 1$. Using this heparin-conjugated hyaluronan hydrogel, a range of loaded TGF- $\beta 1$ doses from 0.25 to $50 \mathrm{ng} / \mathrm{scaffold}$ is tested on encapsulated chondroprogenitor cells for viability, proliferation and cartilaginous matrix deposition. We unravel an increase of all parameters together with the initially entrapped dose of GF up to $20 \mathrm{ng} / \mathrm{scaffold}$, with $5 \mathrm{ng}$ TGF- $\beta 1 / \mathrm{scaffold}$ being the minimum dose to promote chondrogenesis. We also demonstrate the necessity of a sustained release of TGF- $\beta 1$, as no 
matrix deposition is observed upon a burst release. In conclusion, our biomaterial loaded with an optimal initial dose of $5 \mathrm{ng} / \mathrm{scaffold}$ TGF- $\beta 1$ is a promising injectable scaffold for cartilage repair, with potentially increased safety due to the low GF dose, locally administered.

Keywords: hyaluronan; Heparin; chondroprogenitors; TGF- $\beta$; cartilage; injectable

\section{Graphical abstract:}
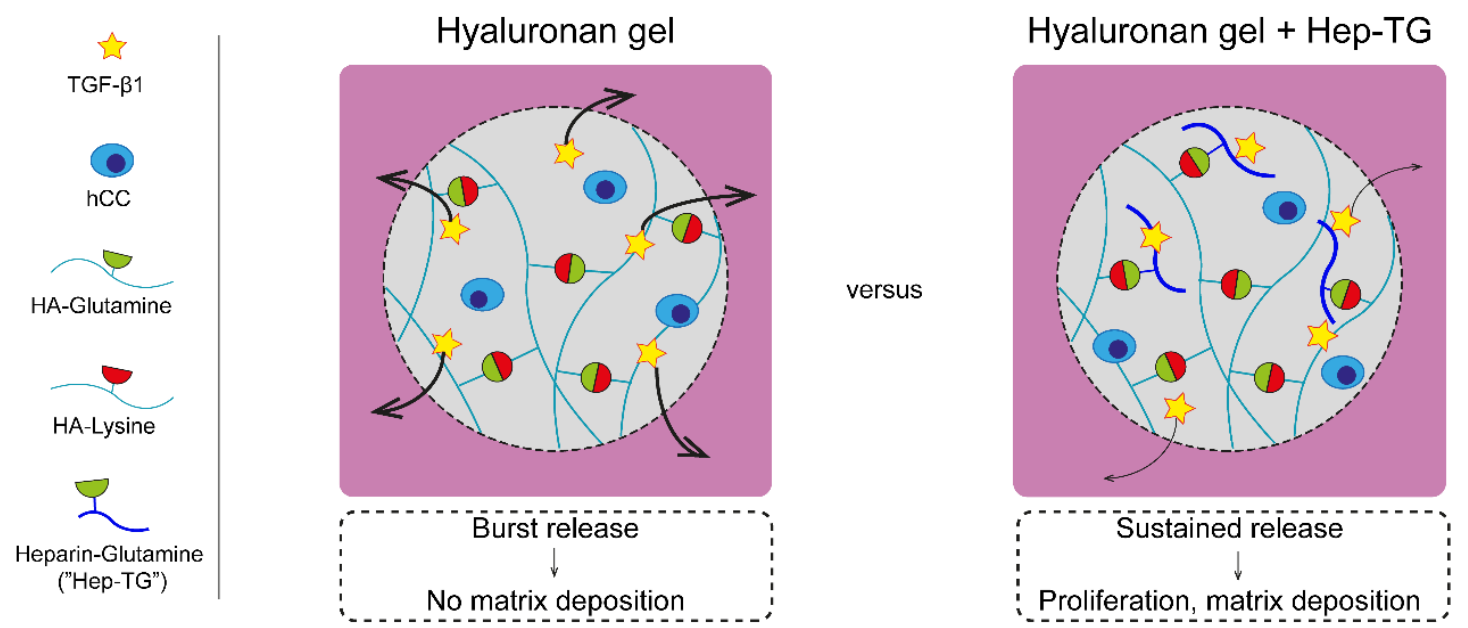

\section{Introduction}

Full-thickness focal chondral defects are common among athletes, with an overall prevalence of $36 \%$ [1]. However, due to the cartilage low cellularity and lack of vasculature, this tissue has a well-known poor self-healing capacity [2]. Treatment of cartilage lesions therefore requires a surgical procedure [3]. The gold standard is Autologous Chondrocyte Implantation (ACI), which relies on the isolation of the patient's own chondrocytes from a low-loadbearing region of the joint, followed by an expansion phase in vitro and later re-implantation in the defect $[4,5]$. Although this technique has provided good clinical results, especially for lesions larger than 5 $\mathrm{cm}^{2}[6,7]$, it is associated with two main drawbacks. Firstly, the graft requires a long maturation time to reach a hyaline-like quality of repaired tissue [8]. Secondly, the procedure is invasive as it includes two steps; the second being an invasive arthrotomy associated with long rehabilitation periods. The invasiveness of the $\mathrm{ACl}$ technique has motivated the development of injectable materials, which could be delivered via arthroscopy [9]. Such materials include the commonly used fibrin glue (Tisseel from Baxter) or Novocart Inject from Tetec, which has reached the stage of clinical trials [10]. However, although injectable, these biomaterials do 
not have the intrinsic property of stimulating chondrogenesis; hence the need for smart biomaterials containing bioactive cues such as growth factors (GF) to guide the redifferentiation.

GFs are soluble proteins acting in a paracrine or autocrine manner to stimulate cell growth [11]. In the field of cartilage repair, they are used either supplemented in the culture medium or present in a 3D matrix with or without encapsulated cells (condition referred to as "loaded") $[14,15,16]$. TGF- $\beta$ signaling has been demonstrated to be critical for cartilage morphogenesis $[16,17,18]$. TGF- $\beta 1$, the predominant isoform in cartilage [19] is involved in cartilage embryonic development $[16,18,20]$, maturation at the postnatal stage, and cartilage homeostasis during adulthood, [18, 22, 23]. TGF- $\beta$ s have consequently been extensively used to stimulate chondrogenesis for cartilage tissue engineering [24 - 26].

In rodents, doses as high as $600 \mathrm{ng}$ (200 ng injected three times in 4 days to stimulate cartilage repair in an arthritis model) [31] or even $1 \mu \mathrm{g}$ of TGF- $\beta 1$ [32] have been injected in the knee joint in the study to study the role of TGF- $\beta 1$ in the pathophysiology of arthritis. Such high doses have been reported to cause pathological effects including inflammation [32], off-target effects including synovial hyperplasia and osteophyte formation [33, 34]. Moreover, TGF- $\beta 1$ is a potent molecule active in the picomolar range in vivo and this activity at low doses is linked to a risk of tumorigenesis due to overstimulation of proliferation, upon exposure to supraphysiological doses $[11,35]$. The side effects of TGF- $\beta 1$ support the need for a local delivery of GFs in the lesion site and more appropriately loaded into a scaffold.

A low dose of GF with a sufficiently long exposure to the encapsulated cells in the site of injury are thus two desired features for use in the clinics, which would justify the need for scaffolds promoting a sustained release of the GF. Indeed, systems where the GF is unbound and quickly diffuses into the synovial fluid (condition referred to as "burst release") may not provide sufficient chondrogenesis stimulation. Several approaches have been developed to achieve a sustained release from hydrogels [36, 37]. Loading strategies more specific to GFs [38 - 41] and more precisely to TGF- $\beta 1$ [25] have been reviewed. Among these strategies, 
sequestration of growth factors by glycosaminoglycans (GAGs) is an interesting approach as it mimics the way GFs are bound to the sulfated polysaccharides of the extracellular matrix (ECM) in native cartilage tissue $[42,43]$. Chondroitin sulfate has been covalently incorporated in a covalently-crosslinked polyethylene glycol network and was shown to allow a slow release of BMP-2, which could be tuned with the ratio of chondroitin sulfate in the system [44]. Similarly, heparan sulfate binds with high affinity to a myriad of proteins, including GFs, to regulate their availability and signaling [45]. Its hypersulfated form, heparin, is extensively used in the clinics for its anti-thombotic properties and has also interestingly been shown to stabilize the proteins it binds to such as FGF2, by protecting FGF2 against acidic or heat treatment [46] and by increasing FGF2 shelf-life during storage [47]. Among the heparin-binding proteins is TGF- $\beta 1$ $[48,49]$. Heparin has consequently been used for drug delivery purposes in the context of tissue engineering $[50,51]$, either incorporated as a semi-interpenetrated polymer within a crosslinked network $[52,53]$ or covalently bound to a polymer backbone. The covalent binding of heparin was achieved in different ways, by grafting tyramine [54], methacrylate or thiols [55] or maleimides [56] moieties to the heparin chains. All these studies using covalently-bound heparin aimed at enhancing the biological properties of the hydrogels. However, despite mentioning the capacity of heparin to bind TGF- $\beta$, they all have used TGF- $\beta$ supplemented within the medium when investigating chondrogenesis of encapsulated cells.

Heparan sulfate is present at the stage of embryonic and fetal development, which provides an interesting feature for its use in combination with young chondroctyes. Chondrocytes from infant $[57,58]$ or fetal $[59]$ donors have been investigated due to their higher proliferation capacity and better retention of chondrogenic phenotype during expansion compared to adult chondrocytes that drift to a more fibroblastic phenotype [60, 61]. More particularly, human chondroprogenitor cells (hCCs) from fetal origin have shown great promises for cartilage tissue engineering. They were used in combination with TGF- $\beta$, either seeded on commercially available collagen sponges [62] or encapsulated in a hyaluronan-based hydrogel, enzymatically crosslinked with transglutaminase factor XIII (also referred to as HA-TG, for Hyaluronan-Transglutaminase [63]) [64]. The potential of the combination of HA-TG and hCCs 
113 for cartilage repair was investigated in vitro with TGF- $\beta 3$ medium supplementation [64]. With

114 a view to developing an injectable therapy for cartilage repair, administered via arthroscopy

115 without any pre-culture step, the GF should be injected together with the cells for maturation

116 of the construct in vivo. This is the limitation to translation of the majority of in vitro studies

117 focused on cartilage regeneration strategies, which use GF medium supplementation whether

118 it is to determine the GFs nature and dose $[65,66]$ or exposure time [67] for the best

119 chondrogenesis stimulation.

120 To our knowledge, no other study has focused on using a biomaterial allowing a sustained 121 release of a wide range of molecules (in the case of this study, heparin-binding molecules) as

122

123

124 a screening platform to better understand the role of a given molecule in the complex process of chondrogenesis. In this study, we characterized a strategy to load TGF- $\beta 1$ in the HA-TG system, to avoid a burst release. Since hCCs have not been extensively studied with regards to their response to TGF- $\beta 1$, heparin-conjugated HA-TG was used as a tool to screen TGF- $\beta$ concentrations to better understand the correlation of the GF dose and the quality of the generated tissue engineered product. We further assessed whether the assumption that a sustained rather than a burst release is the most effective way of stimulating hCCs chondrogenesis. Figure 1.

\section{Material and methods}

\subsection{HA-TG and HA-TG/Hep-TG synthesis and characterization}

2.1.1. Synthesis

The synthesis of HA-TG was done as previously described [63, 64], by covalently grafting high molecular weight Hyaluronan (Lifecore) with transglutaminase peptides, either a Lysine-donor peptide (FKGG-ERCG, HA-Lys) or a Glutamine-acceptor peptide (NQEQVSPL-ERCG, HAGIn). The synthesis of Hep-TG was performed using the same protocol. $100 \mathrm{mg}$ (in other terms $0.168 \mathrm{mmol}$ of carboxylic acid moieties, considering a molecular weight of $593 \mathrm{~g} / \mathrm{mol}$ for a disaccharide repeat unit) of Heparin (Sigma-Aldrich) was dissolved in miliQ water. Once solubilized, $1.5 \mathrm{mmol}$ of MES hydrate (Applichem), $0.025 \mathrm{mmol}$ of 3,3"-Dithiobis(propanoic dihydrazide) (Frontier Scientific) and 0.05 mmol of 1-Ethyl-3-(3- 
142 dimethylaminopropyl)carbodiimide, to obtain $15 \%$ substitution of the carboxylic acid moieties.

143 After leaving overnight to react (> 16 hours), the solution was reduced by addition of $0.15 \mathrm{mmol}$

144 of tris(2-carboxyethyl)phosphine (Fluorochem) for 8 hours and subsequently dialysed against 145 acidified miliQ water after addition of $20 \mathrm{mmol}$ of $\mathrm{NaCl}$ (24 hours, 6 water changed). The 146 thiolated heparin was then added dropwise into a Triethanolamine buffer solution $(0.395 \mathrm{ml}$ of 147 Triethanolamine in $8 \mathrm{ml}$ of miliQ water, $\mathrm{pH}$ 8) containing $2.5 \mathrm{mmol}$ of Divinylsylfone (Sigma), 148 left to react for 2 hours, supplemented with $70 \mathrm{mmol}$ of $\mathrm{NaCl}$ and dialysed against water. The 149 grafting of vinylsulfone moieties was confirmed with NMR (Fig. A). In the last step, the pH was adjusted to 8 , the vinylsulfonated heparin was bubbled with nitrogen to avoid oxidation of the peptides, and a 1.5 -fold excess $(0.04 \mathrm{mmol})$ of Glutamine-donor peptide (NQEQVSPL-ERCG) was added. The full substitution of vinylsulfone moieties by the peptides was confirmed with NMR with the absence of vinylsulfone peak (Fig. A). Starting material (hyaluronan and heparin) and final products (HA-TG, Heparin-TG) were tested for endotoxins using the QUANTI-Blue ${ }^{\mathrm{TM}}$ test from InvivoGen, according to manufacturer's protocol. Results were negative (lower than the detection limit) for all final products (Fig. A).

\subsubsection{HA-TG/Hep and HA-TG/Hep-TG gelation}

158

To make HA-TG/Hep and HA-TG/Hep-TG, polymers were resuspended in a solution of "TBG" buffer (100 mM Glucose, $50 \mathrm{mM}$ Tris base, $50 \mathrm{mM} \mathrm{CaCl}_{2}$, balanced to $\mathrm{pH} 7.6$ ), a doubleconcentrated solution of HA-TG $(4 \% \mathrm{w} / \mathrm{v})$ was mixed with a double-concentrated solution of heparin or heparin-TG $(0.2 \% \mathrm{w} / \mathrm{v})$. Of note, the ratio HA-Lys / HA-GIn was kept at $50 \%$ due to the minimal amount of Hep-GIn added in the system (20 times less than HA-TG). In case of growth factor loading, the appropriate amount of a highly concentrated stock solution (100 $\mu \mathrm{g} / \mathrm{ml}$ ) of TGF- $\beta 1$ (Peprotech AF-100-21C) was added to the heparin vial for at least 15 minutes to read equilibrium binding, prior to the mixing of HA-TG and heparin. Gelation was triggered by adding of Thrombin (Baxter, 1/40 th of the total volume of gel) and Transglutaminase FXIII (Fibrogammin from CSL Behring, $1 / 20^{\text {th }}$ of total volume of gel) and pipetting up and down before casting $25 \mu$ in PDMS hollow cylindrical molds of 1-2 $\mathrm{mm}$ high 
and $4 \mathrm{~mm}$ internal diameter. The casted mixture was kept 15 minutes at $37^{\circ} \mathrm{C}$ before addition

171 of culture medium.

\subsection{Rheometry}

173

The gel precusors were mixed to obtain a total volume of $50 \mu$, without cells. Gelation was triggered by addition of $1.25 \mu \mathrm{l}$ of thrombin and $2.5 \mu \mathrm{l}$ of FXIII and stirring for 3 seconds. Of this gelling mixture, $40 \mu \mathrm{l}$ was loaded on an Anton Paar MCR 301 rheometer. The rheometer was prepared with a $20 \mathrm{~mm}$ plate-plate geometry, a metal floor pre-heated to $37^{\circ} \mathrm{C}$, a surrounding of wet tissue to create a humidified environment. The probe was lowered to 0.1 $\mathrm{mm}$ and the measurement was made at $1 \mathrm{~Hz}$ with $4 \%$ strain.

\subsection{Cell encapsulation and live imaging}

\subsection{1. $\quad$ hCCs expansion and encapsulation}

hCCs were isolated at the Lausanne University Hospital (CHUV) in the Unit of Regenerative Therapy as previously described (Ethics from Centre Hospitalier Universitaire Vaudois Ethics Committee Protocol No.62/07 and registered under the Federal Transplantation Programme complying with the law and Biobank procedures) [59, 64]. A working cell bank of hCCs at passage 2 was prepared for the study. Frozen vials were thawed and in Dubelcco's modified Eagle's medium 41966 (DMEM, Gibco) supplemented with 10\% v/v FBS (Gibco), 1\% (2 mM) L-glutamine (Gibco) and 1\% (100 U/ml) Penicillin-Streptomycin (Gibco).

After a one-week expansion, the cells were trypsinized (i.e. used at passage 3 ) and mixed with the gel precursors at a concentration of $15.10^{6}$ cells $/ \mathrm{ml}$. After gelation as described above, the scaffolds were cultured in "control medium", consisting of DMEM 31966 supplemented with 10 $\mu \mathrm{g} / \mathrm{ml}$ Gentamicin (Gibco), $50 \mu \mathrm{g} / \mathrm{ml}$ L-ascorbate-2-phosphate, $40 \mu \mathrm{g} / \mathrm{ml} \mathrm{L-proline,} \mathrm{1 \%} \mathrm{ITS+}$ Premix (Corning), at $37^{\circ} \mathrm{C}, 5 \% \mathrm{v} / \mathrm{v} \mathrm{CO}_{2}$ with 3 changes of medium per week. Only in the "Med." condition, $10 \mathrm{ng} / \mathrm{ml}$ of TGF- $\beta 1$ was added in the culture medium.

\subsubsection{Live dead staining}

Cellular viability was investigated using a standard Live Dead assay, according to manufacturer's instructions. Briefly, the gels after in vitro culture were immersed in a solution of DMEM (Gibco, 31966) with $2 \mu \mathrm{M}$ Calcein AM, $20 \mu \mathrm{M}$ propidium iodide (Thermofisher) and $10 \mu \mathrm{g} / \mathrm{ml}$ Hoescht, for 1 hour in the incubator $\left(37^{\circ} \mathrm{C}, 5 \% \mathrm{CO}_{2}, 95 \%\right.$ humidity). After 3 washes in pre-warmed PBS, samples were imaged with a ZEISS AxioObserver inverted epifluorescence microscope (ApoTome.2) at 10x magnification, using the ZEN software. All 
204 quantifications were performed with Fiji software. The viability was calculated by dividing the 205 number of living cells by the total number of cells (live + dead) and averaging the values of the 206 triplicates.

\subsection{Biochemical analysis}

\subsubsection{Samples preparation}

The scaffolds were frozen at $-80^{\circ} \mathrm{C}$ and lyophilized overnight. They were digested by adding $500 \mu \mathrm{l}$ of a $270 \mu \mathrm{g} / \mathrm{ml}$ solution of papain from Papaya Latex (Sigma Aldrich) in a buffer containing $5 \mathrm{mM}$ L-cysteine $\mathrm{HCl}, 50 \mathrm{mM}$ sodium phosphate, $2 \mathrm{mM}$ EDTA in miliQ water, with a $\mathrm{pH}$ adjusted to 6.3 . The digestion was done at $60^{\circ} \mathrm{C}$ overnight with shaking (1000 rpm).

\subsubsection{DNA quantification (Picogreen $®$ )}

The amount of DNA was quantified using a Quant-iT PicoGreen® dsDNA assay kit (Invitrogen) as per manufacturer's protocol. Briefly, the samples were pre-diluted 1:10 in TE buffer. $50 \mu$ of this dilution was transferred in a 96-well plate and $50 \mu \mathrm{l}$ of a Picogreen solution was added. The fluorescence was measured with a microplate reader (excitation $480 \mathrm{~nm}$, emission 520 $\mathrm{nm})$. The DNA content was noted as $\mu \mathrm{g}$ DNA/scaffold, normalized to day 0 .

\subsection{3. $\quad$ DMMB assay}

The amount of GAGs was assessed using dimethylmethylene blue solution (21 mg of 1, 9dimethyl methylene blue zinc chloride double salt in $5 \mathrm{ml}$ absolute ethanol with $2 \mathrm{~g}$ sodium formate, further diluted in $800 \mathrm{ml}$ miliQ water; $\mathrm{pH}$ was adjusted to 3 with concentrated formic acid the volume was topped to $1 \mathrm{~L}$ with miliQ water). $40 \mu \mathrm{l}$ of the digested sample (1:200 dilution in papain buffer to obtain values within the linear range of the standard curve) were transferred into a 96-well plate and $100 \mu \mathrm{l}$ of DMMB solution added to the wells. The absorbance at $595 \mathrm{~nm}$ was measured on a microplate reader and the corresponding amount extrapolated from a linear regression of a standard curve. This latter was obtained with either chondroitin 4-sulphate sodium salt from bovine trachea (Sigma-Aldrich, 0 to $50 \mu \mathrm{g} / \mathrm{ml}$, used for scaffolds containing cells after 3 weeks of culture) or a solution of heparin or heparin-TG (0 to $100 \mu \mathrm{g} / \mathrm{ml}$ for heparin release experiments). GAG contents were reported per sample or 
normalized to the day 0 background (important when comparing HA-TG and HA-TG/Hep-TG, considering the sulfates moieties of heparin).

\subsection{Histological analysis}

234 The gels were fixed in $4 \%$ formaldehyde for 1 hour and dehydrated by immersion in gradually 235 increasing ethanol concentration baths. Paraffin impregnation was done in an automated 236 processor (LogosJ, Milestone SRL) and the samples were embedded so that they can be cut 237 coronally (one section showing the middle of the gel, top to bottom). 5- $\mu$ m thick sections were 238 cut at the microtome, deparaffinized in xylene and rehydrated in ethanol baths of decreasing concentration. Immunohistochemistry stainings of collagen I and II included an antigen retrieval step $\left(1200 \mathrm{U} / \mathrm{ml}\right.$ of hyaluronidase (Sigma) for 30 minutes at $37^{\circ} \mathrm{C}$ ), a blocking step with $5 \%$ Normal Goat Serum (NGS, Abcam) in PBS for 1 hour at room temperature. Rabbit

242 anti human primary antibodies diluted in 1\% NGS in PBS (collagen type II antibody: Rockland, 600-401-104, 1:200 / collagen type I antibody: Abcam, \#ab138492, 1:1500) were applied overnight at $4^{\circ} \mathrm{C}$. After rinsing and quenching of the endogenous peroxidase activity $(1 \% \mathrm{H} 2 \mathrm{O} 2$ in water for 20 minutes), slides were incubated with a goat anti-rabbit IgG-HPR (Abcam, ab6721, 1:1500 dilution in 1\% NGS in PBS) for 1 hour at room temperature. The DAB kit (Abcam) was used to reveal the antibodies (4 minutes), as per manufacturer's protocol.

248 Staining with Safranin O was done in accordance with standard protocols. All stainings were 249 followed by a dehydration step in increasing concentrations of ethanol and two baths of xylene before mounting the slides with a resin mounting media (Eukritt). Images were acquired using a Slide Scanner (Pannoramic 250 Flash II).

\subsection{Gene expression with q-RT-PCR}

After 21 days of culture, the scaffolds were snap frozen in liquid nitrogen and crushed in $1 \mathrm{ml}$ of Trizol with pellet pestles (Thomas Scientific) and $200 \mu \mathrm{l}$ of chloroform. After 15 minutes incubation at RT, the tubes were spun 10 minutes at 12 '000 g prior to total RNA extraction with a NucleaoSpin $\circledast$ miRNA kit (Macherey-Nagel), according to manufacturer's protocol. The RNA concentration was quantified with a microplate reader Synergy H1 (BioTek Instruments) and 
PCR experiments. $195 \mathrm{ng}$ of RNA were reverse transcribed, in a $20 \mu \mathrm{l}$ reaction volume and

260

261

262

263

264

265 further processed as previously described in [62]. PCR amplification was performed with SYBR Green (Applied Biosystems) with $150 \mathrm{nM}$ of both forward and reverse primers, which were designed across exon-exon junctions and used in previous studies [62, 64]. Each condition was tested in triplicates, with 2-3 readings per replicate. The analysis utilized the $2^{-\Delta \Delta C t}$ method and results were normalized to a reference gene RPL13a. Cells at day 0 were chosen as the reference.

\subsection{Unconfined compression testing}

The mechanical testing was performed with a TA.XTplus Texture Analyser (Stable Microsystems) with a $500 \mathrm{~g}$ load cell and a $2 \mathrm{~mm}$ diameter cylindrical probe. The gels were subjected to a $0.2 \mathrm{~g}$ preload to ensure the contact between the gels and the probe. The gels were compressed to a final strain of $10 \%$, at a loading rate of $0.01 \mathrm{~mm} / \mathrm{s}$. The $\mathrm{E}$ modulus (compression modulus, $\mathrm{kPa}$ ) was determined as the slope of the linear part of the stress-strain curve.

\subsection{Statistical analysis}

All experiments were performed in triplicates (viability, gene expression, histology) or quadruplicates (compression test, biochemical assays) [exception of duplicates for the growth factor screen histology in Fig. C]. Two (biochemical assays) or three (viability, q-RTPCR) technical replicates were read. Quantitative assays are reported as mean \pm standard deviation of the replicates (each single point is the average of the 2 or 3 technical replicates for each sample). All statistical test were performed with Prism (GraphPad Software Inc., version 7.0.3). Comparisons of the different TGF- $\beta 1$ doses were done with one-way ANOVAs followed by Tukey's post hoc tests comparing each condition to the "M" (TGF- $\beta 1$ supplemented in the medium) condition. For a specific dose of TGF- $\beta 1$, comparisons between HA-TG and HA-TG/Hep-TG were done using an unpaired, two-tailed Student $t$ test. Statistical significance was considered when $p<0.05$ (noted "*”; $p<0.01$ denoted as "**" and $p<0.001$ as “***”, $p<0.0001$ as “****”).

\section{Results}


289 We first investigated whether the addition of heparin to sustain the release of a GF from HA-

290 TG led to better retention of the GF when heparin was simply mixed with HA-TG (thus forming 291 a polymer blend, "HA-TG/Hep") or covalently bound (leading to a graft copolymer, "HA292 TG/Hep-TG").

293 An important feature of HA-TG is its rapid gelation onset and equilibration, which allows a 294 possible administration via an arthroscopy probe and a polymerization in situ within the 295 cartilage defect. To determine whether the addition of heparin in the HA-TG system modifies 296 the gelation behavior, we characterized the gelation kinetics of HA-TG/Hep and HA-TG/Hep297 TG with a rheometer. As previously described, HA-TG gelation reaches a plateau after 10 298 minutes. Hep-TG interfered with HA-TG crosslinking, without reinforcing the mechanical 299 properties due to its small molecular weight. This observation was also reported in another system based on covalent crosslinking of heparin-tyramine to dextran-tyramine [54]. The delayed crosslinking and lower storage modulus after 50 minutes was supposedly due to the competition with the crosslinking of the gel precursors (the HA chains grafted with either a Glutamine-donor peptide or a Lysine-acceptor peptide), as suggested by the absence of crosslinking delay when unmodified heparin is added. This observation did not rule out the possibility to add Hep-TG to the system since the formation of a gel could still be observed ( $G^{\prime}$ and G" curves crossed after $\sim 2$ minutes) (Fig. 2A).

In a second step, we monitored the amount of heparin diffusing out of the gels over two weeks, using a biochemical DiMethyl Methylene Blue (DMMB) assay. As a control, we monitored the presence of GAGs released from HA-TG scaffolds, which was negative at all timepoints (data not shown). We observed a fast diffusion of heparin when it was not crosslinked, with $\sim 35 \%$

311 of the initial loaded amount released from HA-TG/Hep scaffolds at the first investigated 312 timepoint of 2 hours (Fig. 2B). On the other hand, covalent binding of heparin (Hep-TG) allowed 313 better retention in the HA-TG/Hep-TG scaffolds ( 6\% released after 2 weeks $v s \sim 70 \%$ for 314 unbound heparin, $p<0.0001)$. 
Interestingly, both heparin incorporation strategies allowed a sustained release of TGF- $\beta 1$ as shown by the overlapping release curves (Fig. 2C). In absence of heparin, there was a clear burst release of TGF- $\beta 1$ from HA-TG scaffolds, as expected [38]. Indeed, $49 \pm 2 \%$ of the initially loaded amount diffused out after 2 hours and $75 \pm 3 \%$ already at the second time point ( 9 hours). At the end of the two-week experiment, the total amount of TGF- $\beta 1$ released from HA-TG gels was $97 \pm 3 \%$ of the initial amount, vs $60 \pm 4 \%$ upon addition of Hep-TG $(p<0.0001)$ and $60 \pm 2 \%$ for unbound heparin $(p<0.0001)$. Despite the same GF release profile upon incorporation of bound and unbound heparin to HA-TG, extracellular matrix (ECM) deposition by encapsulated hCCs was not promoted by addition of unbound heparin (Fig. 2D). We therefore chose HA-TG/Hep-TG for further investigations. Figure 2.

3.2. Covalent addition of heparin to HA-TG does not hinder the chondroinductive properties of HA-TG

We first sought to characterize the capacity of HA-TG/Hep-TG in TGF- $\beta 1$-supplemented medium to stimulate proliferation of, and cartilaginous matrix deposition by hCCs after 21 days of culture. The goal was to confirm that HA-TG/Hep-TG did not impair the previously described chondro-inductive properties of HA-TG [64] and to validate the use of HA-TG/Hep-TG in TGF$\beta 1$-supplemented medium as a control condition for a TGF- $\beta 1$ dose screening.

We observed similar viability $(79 \pm 3 \%$ in HA-TG vs $78 \pm 3 \%$ in HA-TG/Hep-TG, $\mathrm{p}=0.56)$ and proliferation (3.1-fold increase of DNA content compared to day 0 in HA-TG vs 2.8 in HATG/Hep-TG, p=0.07) of hCCs in both scaffolds (Fig. 3B). The quantification of deposited GAGs showed less accumulation over 3 weeks upon addition of Hep-TG (1.6-fold increase compared to the background at d0 in HA-TG/Hep-TG vs 3.0 in HA-TG, p=0.01). However, the gene expression level of the GAGs core protein, aggrecan, was similar in both conditions at day 21 $(p=0.32$, Fig. 3C). Additionally, gene expression of collagens, both type I and II, was similar in both biomaterials ( $p=0.5$ for type I gene expression and $p=0.08$ for type II) (Fig. 3D). We measured a lower compressive modulus at day 21 for HA-TG/Hep-TG constructs (76 $\pm 4 \mathrm{kPa}$ ) compared to HA-TG ones ( $88 \pm 5 \mathrm{kPa}, \mathrm{p}=0.009$, Fig. $3 \mathrm{E}$ ), which could partly be explained by the rheological observations (Fig. 2A). Indeed, rheological data highlighted a lower storage 
343 modulus still after 50 minutes of crosslinking (540 $\pm 60 \mathrm{~Pa}$ for HA-TG vs $210 \pm 10 \mathrm{~Pa}$ for HA344 TG/Hep-TG, p=0.0006 after unpaired). However, the stiffness of $76 \mathrm{kPa}$ measured after 21 345 days, is within the range of compression moduli obtained after 3 weeks of culture of hCCs encapsulated in 1\% (150 kPa) and 2\% (25 kPa) HA-TG in TGF- 33 supplemented medium [64]. We therefore concluded that HA-TG/Hep-TG is suitable to pursue the development of an injectable cartilage tissue engineering approach. We used this biomaterial as a platform to screen TGF- $\beta 1$ concentrations, to find a range of initially loaded doses of the GF that stimulates chondrogenesis in vitro and to further understand the correlation between this initial dose and hCCs phenotype. Figure 3.

\section{3. hCCs show a dose-response to the initially loaded dose of TGF- $\beta 1$ in terms of viability and proliferation}

We quantified the effect of the initially loaded dose of TGF- $\beta 1$ on the viability and the proliferation of hCCs after 3 weeks of culture in a defined, serum- and GF-free culture medium. We compared the values to the previously described condition of $10 \mathrm{ng} / \mathrm{ml}$ TGF- $\beta 1$ supplementation in medium ("M" condition).

Quantification of Live-dead images showed that the more TGF- $\beta 1$ initially loaded in HATG/Hep-TG, the higher the viability. Indeed, the viability after the 3 weeks of culture in serumand TGF- $\beta 1$-free medium became significantly lower than in the TGF- $\beta 1$ supplemented medium, from a dose of $1.25 \mathrm{ng} / \mathrm{scaffold}(\sim 50 \%$ vs $80 \%, \mathrm{p}=0.03)$ and under $(\mathrm{p}<0001$ for 0.25 and $0 \mathrm{ng} / \mathrm{scaffold}$ ) (Fig. 4B). The lowest dose, $0.25 \mathrm{ng} / \mathrm{scaffold}$, did not prevent cell death as the viability was similarly low as in scaffolds not loaded with TGF- $\beta 1$ ( $20 \%)$. Interestingly, we could also observe a different cell morphology and distribution according to the administration route (medium vs loaded) and the initial dose of TGF- $\beta 1$. When TGF- $\beta 1$ was supplemented in

367 the medium, some cells adopted an elongated shape, radially oriented towards the surface of 368 the gel (Fig. 4D, white arrow), which did not happen when TGF- $\beta 1$ was loaded in the gels. In 369 addition, at $1.25 \mathrm{ng} / \mathrm{scaffold}$ (equivalent to $50 \mathrm{ng} / \mathrm{ml}$ ), we noticed that the cells were not homogeneously distributed, but rather proliferated in clusters (white arrow and dashed circled 371 cluster, Fig. 4D). 
372 Regarding the effect of TGF- $\beta 1$ dose on hCCs proliferation, no dose-response could be 373 observed, but rather a threshold at $1.25 \mathrm{ng} / \mathrm{scaffold}$ ( 2-fold increase of the DNA content 374 compared to $\mathrm{d} 0$ ), under which the proliferation was significantly impacted as compared to the 375 condition of TGF- $\beta 1$-supplemented medium ( $\sim$-fold increase, $p<0.0001)$ (Fig. $4 C$ ). In other 376 words, TGF- $\beta 1$ loaded in HA-TG/Hep-TG promoted proliferation of hCCs, to a similar extent as continuous supplementation in the culture medium, from $5 \mathrm{ng} / \mathrm{scaffold}$ (equivalent to 200 ng/ml) onwards. Figure 4.

3.4. hCCs produce more fibrocartilage and hypertrophic ECM compounds in presence of high amounts of TGF- $\beta 1$

Following the promising viability and proliferation behavior of hCCs upon TGF- $\beta 1$ loading, we further investigated the efficiency of the loading to stimulate cartilaginous ECM production. At $1.25 \mathrm{ng} / \mathrm{scaffold}$, the ECM was deposited pericellularly, and no staining was detected for lower loaded dosages. From 5 ng TGF- $\beta 1 /$ scaffold and higher, the tissue obtained after in vitro culture displayed some hyaline-like features, notably the round shape of the cells, the homogeneously deposited ECM and the intense staining for collagen type II (Fig. 5A). GAGs were also produced as shown by the strong Safranin O staining, with a gradually lower staining intensity with the decrease in TGF- $\beta 1$ loaded amount, suggesting a dose-response of GAG production according to the loaded dosage of the GF (Fig. 5F). GAGs quantification confirmed the histological findings, further highlighting increased amounts of GAGs in scaffolds loaded with $50 \mathrm{ng}(660 \pm 74 \mu \mathrm{g}, \mathrm{p}=0.006), 20 \mathrm{ng}(700 \pm 36 \mu \mathrm{g}, \mathrm{p}=0.001)$ and $5 \mathrm{ng}(600 \pm 85 \mu \mathrm{g}$, $p=0.04)$ of TGF- $\beta 1 /$ scaffold, as compared to the scaffolds cultured with TGF- $\beta 1$ in the medium $(422 \pm 160 \mu \mathrm{g})($ Fig. $5 \mathrm{H})$.

Histological staining additionally displayed features closer to fetal, rather than adult hyaline cartilage tissue, such as a high chondrocytes density and the absence of zonal distribution of 396 chondrocytes [69], which were also reported in ACl grafts 2 to 9 years after surgery [70]. 397 Moreover, collagen type I, present at early stages of cartilage development [71] but also known 398 as a marker of fibrocartilage, was deposited in a dose-dependent manner as shown by the 399 increasing intensity of the staining and the more homogeneous spatial distribution together with the loaded amount of TGF- $\beta 1$ (Fig. 5A). Collagen type X, produced during development 
by chondrocytes undergoing hypertrophy, was also detected by immunohistochemistry for all

402

403

404

405

406

407

408

409

410

411

412

413

414

415

416

doses of TGF- $\beta 1$, in seemingly higher amounts when TGF- $\beta 1$ was loaded in the gel instead of supplemented in the medium (Fig. 5A).

We measured the gene expression of collagens at day 21 . From $5 \mathrm{ng}$ TGF- $\beta 1 /$ scaffold onwards, collagen type II was significantly higher expressed than in the medium supplementation condition ( $p=0.01$ for $50 \mathrm{ng} / \mathrm{scaffold}, \mathrm{p}=0.0007$ for $20 \mathrm{ng} / \mathrm{scaffold}, \mathrm{p}=0.007$ for $5 \mathrm{ng} / \mathrm{scaffold}$ ). Interestingly, $20 \mathrm{ng} / \mathrm{scaffold}$ yielded the best and most reproducible collagen II gene expression increase, suggesting that "the more the better" does not apply for TGF- $\beta 1$ loading (Fig. 4B). Additionally, loading of TGF- $\beta 1$ into HA-TG/Hep-TG led to lower Collagen type I gene expression as compared to day 0 , contrary to medium supplementation that was associated with a 6-fold increase ( $p<0.0001$, Fig. 5 C). Collagen type X gene expression followed the same trend as for collagen type I. Indeed, all conditions with loaded TGF- $\beta 1$ led to a reduced expression as compared to medium-supplemented TGF- $\beta 1$ (12'300 \pm 3'000 with TGF- $\beta 1$ in medium vs $180 \pm 100 / 1 ' 300 \pm 600 / 30 \pm 6 / 14 \pm 8$-fold increase for doses from 50 to 1.25 ng/scaffold respectively, $p<0.0001$ for all conditions, Fig. 5D).

The production of ECM led to increased compression moduli of the scaffolds from $5 \mathrm{ng} / \mathrm{scaffold}$ and higher (Fig. 5E). The initial loading of $5 \mathrm{ng} /$ scaffold resulted in a similar stiffness $(77 \pm 22$ $\mathrm{kPa})$ as the one obtained with TGF- $\beta 1$ medium supplementation $(76 \pm 4 \mathrm{kPa}, \mathrm{p}=0.99)$. Both 50 ng/scaffold (102 $\pm 14 \mathrm{kPa}, \mathrm{p}=0.03)$ and $20 \mathrm{ng} / \mathrm{scaffold}(118 \pm 19 \mathrm{kPa}, \mathrm{p}=0.0005)$ allowed to reach higher compression moduli than medium supplementation. The highest compressive modulus was achieved by loading $20 \mathrm{ng} / \mathrm{scaffold}$, which further strengthens the idea that TGF$\beta 1$ efficiency reaches a plateau at these high doses.

In summary, TGF- $\beta 1$ stimulated hCCs survival, proliferation and cartilaginous matrix deposition, in a dose responsive manner, with a threshold at $5 \mathrm{ng} / \mathrm{scaffold}(200 \mathrm{ng} / \mathrm{ml})$ and a plateau above $20 \mathrm{ng} / \mathrm{scaffold}(800 \mathrm{ng} / \mathrm{ml})$. We thus considered the dose of $20 \mathrm{ng}$ TGF- $\beta 1 / \mathrm{scaffold}$ to test the hypothesis that a sustained release would lead to enhanced chondrogenesis, as opposed to a burst release. Figure 5 .

3.5. The sustained release kinetics of TGF- $\beta 1$ is necessary for hCCs survival, proliferation and ECM production 
430 Little is known about the required timing of TGF- $\beta 1$ exposure to achieve chondrogenesis, and 431 a boost of TGF- $\beta 1$ resulting from a burst release could already be sufficient $[25,72,73]$.

432 The Live-dead staining revealed that despite the burst release from HA-TG, the viability of 433 encapsulated hCCs in HA-TG $(53.3 \pm 9.4 \%)$ remained similar to the one in HA-TG/Hep-TG $434(64.8 \pm 5.9 \%, p=0.15)$ upon exposure to an initial loaded amount of $20 \mathrm{ng}$ TGF- $\beta 1 /$ scaffold. 435 However, proliferation was significantly affected by the burst release $(1.2 \pm 0.5$ DNA fold 436 increase compared to d0 in HA-TG, vs $2.6 \pm 0.1$ in HA-TG/Hep-TG, $p=0.002$ ), as already visible 437 in Live-dead stainings displaying lower cell density in HA-TG (Fig. 6B). In other terms, an initial 438 administration of TGF- $\beta 1$ is sufficient for cell survival but an extended exposure to the GF is 439 needed for proliferation.

440 The stiffness of the HA-TG scaffolds $(6.2 \pm 0.8 \mathrm{kPa})$ was also significantly lower than HA441 TG/Hep-TG $(117.7 \pm 18.7 \mathrm{kPa}, \mathrm{p}<0.0001)$ after 21 days. This correlated with the absence of 442 both GAGs and collagens deposition in HA-TG scaffolds (Fig. 6C-D) as observed on 443 histological stainings. The quantification of GAGs deposition was consistent with histology 444 findings, showing a 2.6 fold increase in the case of a sustained release, vs 1.2 with a burst 445 release $(p=0.002)$. Of note, this increase was due to the proliferation of the cells, as the 446 normalization of GAGs amounts to DNA amounts did not show a significant difference $447(p=0.053)$. The stimulation of GAGs production appeared to be long-lasting since still at day 44821 , hCCs display a $9.2 \pm 1.8$-fold increase of aggrecan gene expression compared to day 0 , 449 vs $0.4 \pm 0.5$ in case of burst release $(p=0.001)$. The observations were the same for collagen 450 type II, with a 39-fold increase of its gene expression in scaffolds with a sustained TGF- $\beta 1$ 451 release $(p<0.0001)$. Inversely, the burst release correlated with a 12-fold increase of collagen type I expression compared to the sustained release system $(p=0.014)$. TGF- $\beta 1$ therefore 453 requires a sustained release to successfully promote matrix deposition and to maintain the 454 chondrogenic phenotype of the cells. Indeed, none of the doses of TGF- $\beta 1$ tested in this study 455 could promote chondrogenesis upon a burst release (Fig. D). Figure 6.

456 4. Discussion 
457 The present study takes place in the context for the search for $\mathrm{ACl}$ improvements, notably 458 through the combination of potential off-the-shelf progenitor cells and smart biomaterials [41] 459 together with stimulating factors [74]. There is a strong interest for injectable scaffolds in the 460 field of cartilage tissue engineering [9], which could represent a manner to provide the patients with a non-invasive surgical approach. For an injectable, this requires development of biomaterials capable of binding GFs to stimulate the regeneration process in vivo. In this study, we report the enhancement of a previously described biocompatible, injectable and chondroinductive biomaterial, HA-TG, in order to add some GF-binding moieties. We report three main findings. Firstly, chemically-modified heparin (Hep-TG) kept its GF binding property as seen by TGF- $\beta 1$ sustained release and could promote matrix production unlike the unbound heparin. Secondly, we found a dose-response for the stimulation of proliferation and matrix production, with $5 \mathrm{ng}$ of TGF- $\beta 1 / \mathrm{scaffold}$ (i.e. $200 \mathrm{ng} / \mathrm{ml}$ ) being the lowest efficient dose and an increasingly fibrocartilaginous composition being observed with higher doses of TGF- $\beta 1$. Thirdly, we found that a sustained release is necessary to stimulate cartilaginous matrix deposition, even with a 471 high initial loaded dose of TGF- $\beta 1$.

472 In the first instance, we investigated the proper way to introduce heparin to the system, namely 473 either semi-interpenetrated in or covalently bound to HA-TG. An important finding of this study 474 is that the sustained release is not the only critical parameter for chondrogenesis as HA475 TG/Hep, despite its capacity to sustain TGF- $\beta 1$ release, did not lead to ECM deposition by 476 hCCs. The persistence of a certain amount of sulfates moieties therefore seems to be an 477 important factor for cartilage regeneration, as suggested by previous studies reporting 478 enhanced chondrocytes redifferentiation upon encapsulation in 3D matrices containing heparin 479 [54-56]. The presence of sulfates is not sufficient per se, because hCCs in HA-TG/Hep-TG 480 cultured in serum- and TGF- $\beta 1$-free medium did not display any ECM deposition (Fig. 4A, F). 481 A possible explanation for the necessity of the persistence of some sulfates moieties in 482 combination with the presence of TGF- $\beta 1$ is that heparin binds to the newly produced ECM 483 after an initial stimulation of chondrogenesis by the GF, as heparin is known to bind collagens 484 and other ECM proteins [75]. These results could also be linked to the capacity of heparin to 
bind to the GF in the direct surrounding of the scaffolds, therefore prolonging the effect of this GF. This hypothesis is supported by the observation in the recently published study of Cavalli et al. [68] of a Collagen type II pericellular deposition by infant chondrocytes in HA-TG/HepTG scaffolds in an ectopic mouse model, even in absence of loaded TGF- $\beta 1$. The concept of enriching the defect site with GFs from the synovial fluid, by injecting a heparan sulfate based gel in a rabbit osteochondral defect model, has also been described and reported good results [76].

The second part of the study consists of a TGF- $\beta 1$ dose screening. Of note, the effect of GFs depends on the cell type used [39]. FGF-2 and IGF-1 did not stimulate extracellular matrix deposition by hCCs, when supplemented in the culture medium at concentrations commonly used in the literature (Fig. C1). TGF- $\beta 3$ was used in a previous study investigating the potential of the combination of hCCs and HA-TG [64]. TGF-ß3 had been shown to enhance neocartilage formation by chondrocytes in vivo when bound to heparin, but was nevertheless also reported not to bind to heparin [53]. We confirmed that TGF- 33 did not bind to the heparin used in our system (Fig. C2) and focused on the heparin-binding isoform TGF- $\beta 1$. The screening also highlighted a dose response with a threshold at $5 \mathrm{ng} /$ scaffold (equivalent to $200 \mathrm{ng} / \mathrm{ml}$ ) to promote chondrogenesis to similar extent as TGF- $\beta 1$ medium supplementation, despite the 9fold reduction of the total amount of GF administered to the cells (considering $10 \mathrm{ng}$ for each medium change, 3 times a week for 3 weeks). Of note, the dose of $200 \mathrm{ng} / \mathrm{ml}$ is close to the reported amount of $300 \mathrm{ng} / \mathrm{ml}$ of TGF- $\beta 1$ present in the native cartilage tissue, in its latent form [78]. This amount is low compared to loaded TGF- $\beta$ doses reported in the literature, such as $50 \mathrm{ng}$ per 4.5-mm diameter, bilayered aginate-PLGA scaffolds [79], 2.5 to $5 \mu \mathrm{g} / \mathrm{ml}$ in fibrin scaffolds [80], $3 \mu \mathrm{g} / \mathrm{ml}$ in a PEG hydrogel [81]. The size of defects treated by $\mathrm{ACl}$ can reach 10 $\mathrm{cm}^{2}$ [83], which would represent, considering a thickness of $2 \mathrm{~mm}$ and the use of a scaffold loaded with $200 \mathrm{ng} / \mathrm{ml}$ of TGF- $\beta 1$, the injection of a total as low as $400 \mathrm{ng}$ of TGF- $\beta 1$. However, we also report increased collagen $X$ deposition for all doses of TGF- $\beta 1$ that were found to stimulate matrix synthesis.. This can be expected considering that exposure to a high amount of TGF- $\beta 1$ can lead to a shift from Smad2/3 to Smad1/5 signaling pathway [85], this latter being 
513 involved in chondrocyte hypertrophy [86]. We can hypothesize that the reduced gene

514 expression levels of Collagen type $X$ at day 21 , which seemingly contradicts histological 515 observations, may be linked to the decreasing concentration of TGF- $\beta 1$ overtime, which 516 suggests that the collagen $X$ deposition phase could be transient. Of note, the production of collagen type I is part of the normal process of cartilage formation [71]. Since fetal cartilage

518 tissue features were observed after 21 days in culture in this study, a longer time point to 519 observe potential ECM remodeling and maturation and change of composition would give 520 more information about whether our system mimics developmental engineering or promotes 521 the deposition of a fibrocartilaginous ECM.

522 Lastly, a brief exposure to a high dose of TGF- $\beta 1$ has been reported to enhance 523 chondrogenesis in vitro $[25,67,82,87,88]$. However, studies focusing on the duration of TGF-

$524 \beta$ administration for stem cell chondrogenesis use various set ups leading to contradicting 525 conclusions, for instance exposure to $5 \mathrm{ng} / \mathrm{ml}$ of TGF- $\beta 1$ during $2 \mathrm{D}$ expansion and pellet assay 526 of human MSCs [88] or $10 \mathrm{ng} / \mathrm{ml}$ after encapsulation of expanded human MSCs in a PEG527 based scaffold [67] or also bovine and equine MSCs expanded with FGF2 and exposed to 10 ng/ml TGF- $\beta 1$ after encapsulation in a self-assembling peptide hydrogel [82]. We compared the efficiency of a burst vs sustained release, using the second highest dose of TGF- $\beta 1$ tested in our dose screening, which led to the highest proliferation, ECM deposition and stiffness (20 $\mathrm{ng} / \mathrm{scaffold}$, i.e. $800 \mathrm{ng} / \mathrm{ml}$ ). We demonstrated that, in the system described in this present 532 study, the sustained release of TGF- $\beta 1$ was necessary for proliferation of hCCs and matrix 533 production. As such, we consider HA-TG/Hep-TG to pursue the development of an injectable, 534 GF-loaded scaffold for cartilage repair.

536 We have shown that covalent addition of heparin to the HA-TG system allows to sustain the release of TGF- $\beta 1$ from HA-TG without affecting its ability to be injectable, biocompatibility or

538 the chondrogenic potential of the cells. We have successfully used this hydrogel as a tool to 539 screen a range of TGF- $\beta 1$ concentrations and determined an efficient dose of loaded TGF- $\beta 1$ 540 between 200 and $800 \mathrm{ng} / \mathrm{ml}$, and showed that the slow release is necessary to stimulate matrix 
deposition by hCCs. This paves the way to an in situ crosslinking, minimally-invasive therapy

542 for cartilage lesions, with increased safety due to the low, sustainably released loaded dose of 543 TGF- $\beta 1$.

\section{Acknowledgements}

545 The authors would like to thank Dr. Nicolas Broguiere for suggesting the strategy of heparin546 TG to load growth factors in HA-TG and establishing the synthesis, Dr. Emma Cavalli for 547 sharing her opinion on the study design and helping for the gene expression experiments, Dr. 548 Mihyun Lee for helping with NMR experiments and Dr. Florian Formica for the scientific input 549 during the project and for commenting the manuscript. The authors acknowledge the use of 550 the Scientific Center for Optical and Electron Microscopy facilities (ScopeM) of ETH Zürich.

\section{Author contributions}

552 Conception and design: C.L, M.Z.W, Acquisition and analysis of the data: C.L, Interpretation 553 of the data: C.L, M.Z.W, Drafting of the article: C.L, Critical revision for important intellectual content: M.Z.W, L.A.A, Final approval of the article: M.Z.W, Provision of study materials and

555 patients' samples: L.A.A. provided the human chondroprogenitor cells

\section{Role of funding source}

557 This work was supported by the Swiss National Science Foundation [grant numbers 315230_159783 and 315230_143667].

\section{Competing interest statement}

None

\section{References}

1. D.C. Flanigan, J.D. Harris, T.Q. Trinh, R.A. Siston, R.H. Brophy, Prevalence of chondral defects in Athletes' Knees: A systematic review. Med Sci Sports Exerc., 42(2010), pp.1795-1801.

2. M.S. Vrahas, K. Mithoefer, D. Joseph, The long-term effects of articular impaction, Clin Orthop Relat Res (1976-2007). 423(2004), pp.40-43.

3. E.A. Makris, A.H. Gomoll, K.N. Malizos, J.C. Hu, K.A. Athanasiou, Repair and tissue engineering techniques for articular cartilage. Nat Rev Rheumatol. 11(2015), pp.21-34.

4. M. Brittberg, A. Lindahl, A. Nilsson, C. Ohlsson, O. Isaksson, L. Peterson, Treatment of deep cartilage defects in the knee with autologous chondrocyte transplantation, N Engl J Med. 331(1994), pp.889-895.

5. P. Niemeyer, D. Albrecht, S. Andereya, P. Angele, A. Ateschrang, M. Aurich, M. Baumann, U. Bosch, C. Erggelet, S. Fickert, H. Gebhard, K. Gelse, D. Günther, A. Hoburg, P. Kasten, T. Kolombe, H. Madry, S. Marlovits, N.M. Meenen, P.E. Müller, U. Nöth, J.P. Petersen, M. Pietschmann, W. Richter, B. Rolauffs, K. Rhunau, B.Schewe, A. Steinert, M.R. Steinwachs, G.H. Welsch, W. Zinser, J. Fritz, Autologous chondrocyte implantation $(\mathrm{ACl})$ for cartilage defects of the knee: a guideline by the working group "Clinical Tissue Regeneration" of the German Society of Orthopaedics and Trauma (DGOU). Knee. 23(2016), pp.426-435.

6. L. Peterson, H.S. Vasiliadis, M. Brittberg, A. Lindahl, Autologous chondrocyte implantation: A long-term follow-up, Am J Sports Med. 38(2010), pp.1117-1124. 
7. L. L. Negrin, Autologous Chondrocyte Implantation Versus Microfracture of the Knee. J Clin Trials, 2(2012), pp.2-4 (Editorial).

8. M. Krill, N. Early, J.S. Everhart, D.C. Flanigan, Autologous chondrocyte implantation (ACl) for knee cartilage defects: A review of indications, technique, and outcomes. J Bone Joint Surg Rev. 6(2018), p.e5.

9. M. Liu, X. Zeng, C. Ma, H. Yi, Z. Ali, X. Mou, S. Li, Y. Deng, N. He, Injectable hydrogels for cartilage and bone tissue engineering, Bone Res. 5(2017).

10. S. Thier, F. Baumann, C. Weiss, S. Fickert, Feasibility of arthroscopic autologous chondrocyte implantation in the hip using an injectable hydrogel. Hip Int. 28(2018), pp.442-449.

11. M. Cross, T.M. Dexter, Growth factors in development, transformation, and tumorigenesis. Cell, 64(1991), pp.271-280.

12. C. Gaissmaier, J.L. Koh, K. Weise, Growth and differentiation factors for cartilage healing and repair. Injury, 39(2008), pp.88-96.

13. LA. Fortier, J.U. Barker, E.J. Strauss, T.M. McCarrel, B.J. Cole, The role of growth factors in cartilage repair. Clin Orthop Relat Res. 469(2011), pp.2706-2715.

14. E. Augustyniak,T. Trzeciak, The role of growth factors in stem cell-directed chondrogenesis : a real hope for damaged cartilage regeneration, Int Orthop. 39(2015), pp.995-1003.

15. A. Spagnoli, L. O'Rear, R.L. Chandler, F. Granero-Molto, D.P. Mortlock, A.E. Gorska, J.A. Weis, L. Longobardi, A. Chytil, K. Shimer, H.L. Moses. TGF- $\beta$ signaling is essential for joint morphogenesis, J Cell Biol. 177(2007), pp.1105-1117.

16. W. Wang, D. Rigueur, K.M. Lyons, TGF- $\beta$ Signaling in Cartilage Development and Maintenance, Birth Defects Res C Embryo Today. 102(2014), pp.37-51.

17. M.B. Albro, R.J. Nims, A.D. Cigan, K.J. Yeroushalmi, T. Alliston, C.T. Hung, G.A. Ateshian, Accumulation of exogenous activated TGF- $\beta$ in the superficial zone of articular cartilage. Biophys J. 104(2013), pp.17941804.

W.S. Toh, B.C. Heng, C.P. Ye, H. Liu, T. Cao, A.J. Rufaihah, Combined effects of TGF $\beta 1$ and BMP2 in serum-free chondrogenic differentiation of mesenchymal stem cells induced hyaline-like cartilage formation. Growth Factors. 23(2005), pp.313-321.

18. X. Yang, L. Chen, X. Xu, C. Li, C. Huang, C.X. Deng, TGF- $\beta /$ Smad3 signals repress chondrocyte hypertrophic differentiation and are required for maintaining articular cartilage. J Cell Biol. 153(2001), pp.35-46.

19. W. Madej, A. van Caam, E. Blaney Davidson, P. Buma, P.M. van der Kraan, Unloading results in rapid loss of TGF $\beta$ signaling in articular cartilage: role of loading-induced TGF $\beta$ signaling in maintenance of articular chondrocyte phenotype? Osteoarthritis Cartilage, 24(2016), pp.1807-1815.

20. E.S. Place, R. Nair, H.N. Chia, G. Szulgit, E.H. Lim, M.M. Stevens, Latent TGF- $\beta$ hydrogels for cartilage tissue engineering. Adv. Healthcare Mater. 1(2012), pp.480-484.

21. H. Madry, A. Rey-Rico, J.K. Venkatesan, B Joh,stone, M. Cucchiarini, Transforming Growth Factor BetaReleasing Scaffolds for Cartilage Tissue Engineering, Tissue Eng Part B Rev. 20(2014), pp.106-125.

22. H. Kwon, N.K. Paschos, J.C. Hu, K. Athanasiou, Articular cartilage tissue engineering: the role of signaling molecules, Cell Mol Life Sci. 73(2016), pp.1173-1194.

23. S. Owen, H. Francis, M. Roberts, Disappearance kinetics of solutes from synovial fluid after intra- articular injection. Br J Clin Pharmacol. 38(1994), pp.349-355.

24. H.L. Glansbeek, E. L. Vitters, Stimulation of articular cartilage repair in established arthritis by local administration of transforming growth factor-beta into murine knee joints, Lab Invest. 78(1998), pp.133142.

25. J.B. Allen, C.L. Manthey, A.R. Hand, K. Ohura, L. Ellingsworth, S.M. Wahl, Rapid onset synovial inflammation and hyperplasia induced by transforming growth factor. J Exp Med. 171(1990), pp.231-247.

26. H.M. van Beuningen, P.M. van der Kraan, O.J. Arntz, W. B. van den Berg, In vivo protection against interleukin-1-induced articular cartilage damage by transforming growth factor-beta 1: age-related differences." Ann Rheum Dis. 53(1994), pp.593-600.

27. H.M. van Beuningen, H.L. Glansbeek, P.M. van Der Kraan, W.B. van Den Berg, Osteoarthritis-like changes in the murine knee joint resulting from intra-articular transforming growth factor- $\beta$ injections. Osteoarthritis Cartilage. 8(2000), pp.25-33.

28. G.C. Blobe, W.P. Schiemann, H.F. Lodish, (2000). Role of transforming growth factor beta in human disease, N Engl J Med. 342(2000), pp. 1350-1358.

29. T.R. Hoare, D.S. Kohane, Hydrogels in drug delivery: Progress and challenges. Polymer. 49(2008), pp.1993-2007.

30. J. Li, D.J. Mooney, Designing hydrogels for controlled drug delivery, Nat Rev Mater. 1(2016), pii:16071.

31. A.K. Silva, C. Richard, M. Bessodes, D. Scherman, O.W. Merten, Growth Factor Delivery Approaches in Hydrogels. Biomacromolecules. 10(2009), pp.9-18.

32. K. Lee, E.A. Silva, D.J. Mooney, Growth factor delivery-based tissue engineering: general approaches and a review of recent developments. J R Soc Interface. 8(2011), pp.153-170.

33. J. Lam, S. Lu, F.K. Kasper, A.G. Mikos, Strategies for controlled delivery of biologics for cartilage repair, Adv Drug Deliv Rev. 84(2015), pp.123-134.

34. J. Yang, Y.S. Zhang, K. Yue, A. Khademhosseini, Cell-laden hydrogels for osteochondral and cartilage tissue engineering. Acta Biomater. 57(2017), pp.1-25. 
35. J.A. Hubbell, Matrix-bound growth factors in tissue repair. Swiss Med Wkly, 136(2006), pp.387-391.

36. E. Öztürk, Ø. Arlov, S. Aksel, L. Li, D.M. Ornitz, G. Skjåk-bræk, M. Zenobi-Wong, Sulfated Hydrogel Matrices Direct Mitogenicity and Maintenance of Chondrocyte Phenotype through Activation of FGF Signaling. Adv Funct Mater. 26(2016), pp.3649-3662.

37. F. Anjum, P.S. Lienemann, S. Metzger, J. Biernaskie, M.S. Kallos, M. Ehrbar, Enzyme responsive GAGbased natural-synthetic hybrid hydrogel for tunable growth factor delivery and stem cell differentiation. Biomaterials, 87(2016), pp.104-117.

38. J.R. Bishop, M. Schuksz, J.D. Esko, Heparan sulphate proteoglycans fine-tune mammalian physiology. Nature, 446(2007), pp.1030-1037.

39. D. Gospodarowicz, J. Cheng, Heparin protects basic and acidic FGF from inactivation, J Cell Physiol. 128(1986), pp.475-484.

40. E.R. Edelman, E. Mathiowitz, R. Langer, M. Klagsbrun, Controlled and modulated release of basic fibroblast growth factor, Biomaterials. 12(1991), pp.619-626.

41. T.A. McCaffrey, D.J. Falcone, B. Du, Transforming growth factor- $\beta 1$ is a heparin-binding protein: Identification of putative heparin-binding regions and isolation of heparins with varying affinity for TGF- $\beta 1$. J Cell Physiol. 152(1992), pp.430-440.

42. J. Lee, S. Wee, J. Gunaratne, R.J.E. Chua, R.A.A. Smith, L. Ling, D.G. Fernig, K. Swaminathan, V. Nurcombe, S.M. Cool, Structural determinants of heparin-transforming growth factor- $\beta 1$ interactions and their effects on signaling. Glycobiology, 25(2015), pp.1491-1504.

43. Y. Liang, K.L. Kiick, Heparin-functionalized polymeric biomaterials in tissue engineering and drug delivery applications, Acta Biomater. 10(2014), pp.1588-1600.

44. Y.K. Joung, J.W. Bae, K. Dong, P. Prof, Controlled release of heparin-binding growth factors using heparincontaining particulate systems for tissue regeneration, Expert Opin Drug Deliv. 5(2008), pp.1173-1184.

45. S.E. Sakiyama-Elbert, J. Hubbell, Development of fibrin derivatives for controlled release of heparinbinding growth factors. J Control Release. 65(2000), pp.389-402.

46. M. Lyon, G. Rushton, J.T. Gallagher. The interaction of the transforming growth factor-beta s with heparin heparan sulfate is isoform-specific. J Biol Chem. 272(1997), pp.18000-8006.

47. R. Jin, L.S. Moreira Teixeira, P.J. Dijkstra, C.A. Van Blitterswijk, M. Karperien, J. Feijen, Chondrogenesis in injectable enzymatically crosslinked heparin/dextran hydrogels. J Control Release. 152(2011), pp.186195.

48. G.C.J. Brown, K.S. Lim, B.L. Farrugia, G.J. Hooper, T.B.F. Woodfield, Covalent Incorporation of Heparin Improves Chondrogenesis in Photocurable Gelatin-Methacryloyl Hydrogels. Macromol Biosci. 17(2017), pp.1-13.

49. E. Hesse, U. Freudenberg, T. Niemietz, C. Greth, M. Weisser, S. Hagmann, M. Binner, C. Werner, W. Richter, Peptide-functionalized starPEG/heparin hydrogels direct mitogenicity, cell morphology and cartilage matrix distribution in vitro and in vivo, J Tissue Eng Regen M. 12(2018), pp.229-239.

50. I.V. Adkisson, H. Davis, J.A. Martin, R.L. Amendola, C. Milliman, K.A. Mauch, A.B. Katwal, M. Seyedin, A. Amendola, P.R. Streeter, J.A. Buckwalter, The potential of human allogeneic juvenile chondrocytes for restoration of articular cartilage, Am J Sports Med. 38(2010), pp.1324-1333.

51. F. Mortazavi, H. Shafaei, J. Soleimani Rad, L. Rushangar, A. Montaceri, M. Jamshidi, High Quality of Infant Chondrocytes in Comparison with Adult Chondrocytes for Cartilage Tissue Engineering, World J Plast Surg. 6(2017), pp.183-189.

52. S. Darwiche, C. Scaletta, W. Raffoul, D.P. Pioletti, L.A. Applegate, Epiphyseal Chondroprogenitors Provide a Stable Cell Source for Cartilage Cell Therapy. Cell Med. 4(2012), pp.23-32.

53. H. Holtzer, J. Abbott, J. Lash, S. Holtzer, The loss of phenotypic traits by differtiated cells in vitro, Proc Natl Acad Sci USA. 46(1960), pp.1533-1542.

54. J.M. Melero-Martin, M. Al-Rubeai, In Vitro Expansion of Chondrocytes, in: N Ashammakhi, R Reis \& E Chiellini (Eds.), Topics in Tissue Engineering, 3(2007), pp.1-37.

55. D. Studer, E. Cavalli, F.A. Formica, G.A. Kuhn, G. Salzmann, M. Mumme, M.R. Steinwachs, L.A. Applegate, K. Maniura-Weber, M. Zenobi-wong, Human chondroprogenitors in alginate - collagen hybrid scaffolds produce stable cartilage in vivo. J Tissue Eng Regen Med. 11(2016), pp.3014-3026.

56. N. Broguiere, L. Isenmann, M. Zenobi-Wong, Novel enzymatically cross-linked hyaluronan hydrogels support the formation of 3D neuronal networks. Biomaterials. 99(2016), pp.47-55.

57. N. Broguiere, E. Cavalli, G.M. Salzmann, L.A. Applegate, M. Zenobi-wong, Factor XIII Cross-Linked Hyaluronan Hydrogels for Cartilage Tissue Engineering. ACS Biomater Sci Eng. 2(2016), pp.2176-2184.

58. T. Blunk, A.L. Sieminski, K.J. Gooch, D.L. Courter, A.P. Hollander, A.M. Nahir, R. Langer, G. VunjakNovakovic, L.E. Freed, (2002). Differential Effects of Growth Factors on Tissue-Engineered Cartilage, Tissue Eng. 8(2002), pp.73-84.

59. J. Parreno, V.J. Bianchi, C. Sermer, S.C. Regmi, D. Backstein, T.A. Schmidt, R.A. Kandel, Adherent agarose mold cultures: An in vitro platform for multi-factorial assessment of passaged chondrocyte redifferentiation, J Orthop Res. 36(2018), pp.2392-2405.

60. A.N. Buxton, C.S. Bahney, J.U. Yoo, B. Johnstone, Temporal Exposure to Chondrogenic Factors Modulates Human Mesenchymal Stem Cell Chondrogenesis in Hydrogels, Tissue Eng Part A. 17(2011), pp.371-380.

61. E. Cavalli, C. Levinson, M. Hertl, N. Broguiere, O. Brück, S. Mustjoki, A. Gerstenberg, D. Weber, G. Salzmann, M. Steinwachs, G. Barreto, M. Zenobi-Wong, Characterization of polydactyly chondrocytes and their use in cartilage engineering. Sci Rep. 9(2019), pp.4275-4290. 
62. I. Ribitsch, R.L. Mayer, M. Egerbacher, S. Gabner, M.M. Kańduła, J. Rosser, E. Haltmayer, U. Auer, S. Gültekin, J. Huber, A. Bileck, D.P. Kreil, C. Gerner, F. Jenner, Fetal articular cartilage regeneration versus adult fibrocartilaginous repair: secretome proteomics unravels molecular mechanisms in an ovine model. Dis Model Mech. 11(2018), pp.1-11.

63. L. Peterson, T. Minas, M. Brittberg, A. Nilsson, E. Sjögren-Jansson, A. Lindahl, Two- to 9-Year Outcome After Autologous Chondrocyte Transplantation of the Knee. Clin Orthop Relat Res. 374(2000), pp.212-234.

64. W. Dessau, H. von der Mark, K. von der Mark, S. Fischer, Changes in the patterns of collagens and fibronectin during limb-bud chondrogenesis. J Embryol Exp Morphol. 57(1980), pp.51-60.

65. E.G. Lima, L. Bian, K.W. Ng, R.L. Mauck, B.A. Byers, R.S. Tuan, G.A. Ateshian, C.T. Hung, The beneficial effect of delayed compressive loading on tissue-engineered cartilage constructs cultured with TGF- $\beta 3$. Osteoarthritis Cartilage. 15(2007), pp.1025-1033.

66. B.A. Byers, R.L. Mauck, I.E. Chiang, R.S. Tuan, Transient Exposure to Transforming Growth Factor Beta 3 Under Serum-Free Conditions Enhances the Biomechanical and Biochemical Maturation of TissueEngineered Cartilage. Tissue Engineering Part A, 14(2008), pp.1821-1834.

67. M. Demoor, D. Ollitrault, T. Gomez-leduc, M. Bouyoucef, M. Hervieu, H. Fabre, J. Lafont, JM. Denoix, F. Auigié, F. Mallein-Gerin, F. Legendre, P. Galera, Cartilage tissue engineering: Molecular control of chondrocyte differentiation for proper cartilage matrix reconstruction, Biochim Biophys Acta Gen Subj. 1840(2014), pp.2414-2440.

68. F. Delacoux, F. Ruggiero, S. Cogne, A. Fichard, R. Garrone, Unraveling the Amino Acid Sequence Crucial for Heparin Binding to Collagen V. J Biol Chem. 275(2002), pp.29377-29382.

69. J.H. Lee, X. Luo, X. Ren, T.C. Tan, R.A.A. Smith, K. Swaminathan, S. Sekar, K. Bhakoo, V. Nurcombe, J.H. Hui, S.M. Cool, A Heparan Sulfate Device for the Regeneration of Osteochondral Defects. Tissue Eng Part A. 25(2018), pp.352-363.

70. M.B. Albro, R.J. Nims, K.M. Durney, A.D. Cigan, J.J. Shim, G. Vunjak-Novakovic, C.T. Hung, G.A. Ateshian, Heterogeneous engineered cartilage growth results from gradients of media-supplemented active TGF- $\beta$ and is ameliorated by the alternative supplementation of latent TGF- $\beta$. Biomaterials. 77(2016), pp.173-185.

71. R. Reyes, A. Delgado, R. Solis, E. Sanchez, A. Hernandez, J.S. Roman, C. Evora. Cartilage repair by local delivery of transforming growth factor-beta1 or bone morphogenetic protein-2 from a novel, segmented polyurethane/polylactic-co-glycolic bilayered scaffold. J Biomed Mater Res A. 102(2014), pp.1110-1120.

72. M. Ahearne, C.T. Buckley, D.J. Kelly, A growth factor delivery system for chondrogenic induction of infrapatellar fat pad-derived stem cells in fibrin hydrogels. Biotechnol Appl Biochem. 58(2011), pp.345-352.

73. C. Stüdle, Q. Vallmajó-Martín, A. Haumer, J. Guerrero, M. Centola, A. Mehrkens, D.J. Schaefer, M. Ehrbar, A. Barbero, I. Martin, Spatially confined induction of endochondral ossification by functionalized hydrogels for ectopic engineering of osteochondral tissues. Biomaterials. 171(2018), pp.219-229.

74. C. Ossendorf, M.R. Steinwachs, P.C. Kreuz, G. Osterhoff, A. Lahm, P.P. Ducommun, C. Erggelet, Autologous chondrocyte implantation $(\mathrm{ACl})$ for the treatment of large and complex cartilage lesions of the knee. Sports Med Arthrosc Rehabil Ther Technol. 3(2011), pp.1-5.

75. P.M. van der Kraan, Differential Role of Transforming Growth Factor-beta in an Osteoarthritic or a Healthy Joint. J Bone Metab. 25(2018), pp.65-72.

76. P.S. Leboy, G. Grasso-Knight, M. D'Angelo, S.W. Volk, J.B. Lian, H. Drissi, G.S. Stein, S.L. Adams, SmadRunx interactions during chondrocyte maturation. J Bone Joint Surg. 83(2001), pp.S1-15.

77. Y. Miura, J. Parvizi, J.S. Fitzsimmons, S.W. O'Driscoll, Brief exposure to high-dose transforming growth factor- $\beta 1$ enhances periosteal chondrogenesis in vitro: A preliminary report. J Bone Joint Surg. 84(2002), pp.793-799.

78. H.J. Kim, Y.J. Kim, G.I. Im, Is continuous treatment with transforming growth factor-beta necessary to induce chondrogenic differentiation in mesenchymal stem cells? Cells Tissues Organs. 190(2009), pp.110. 


\section{Figures}

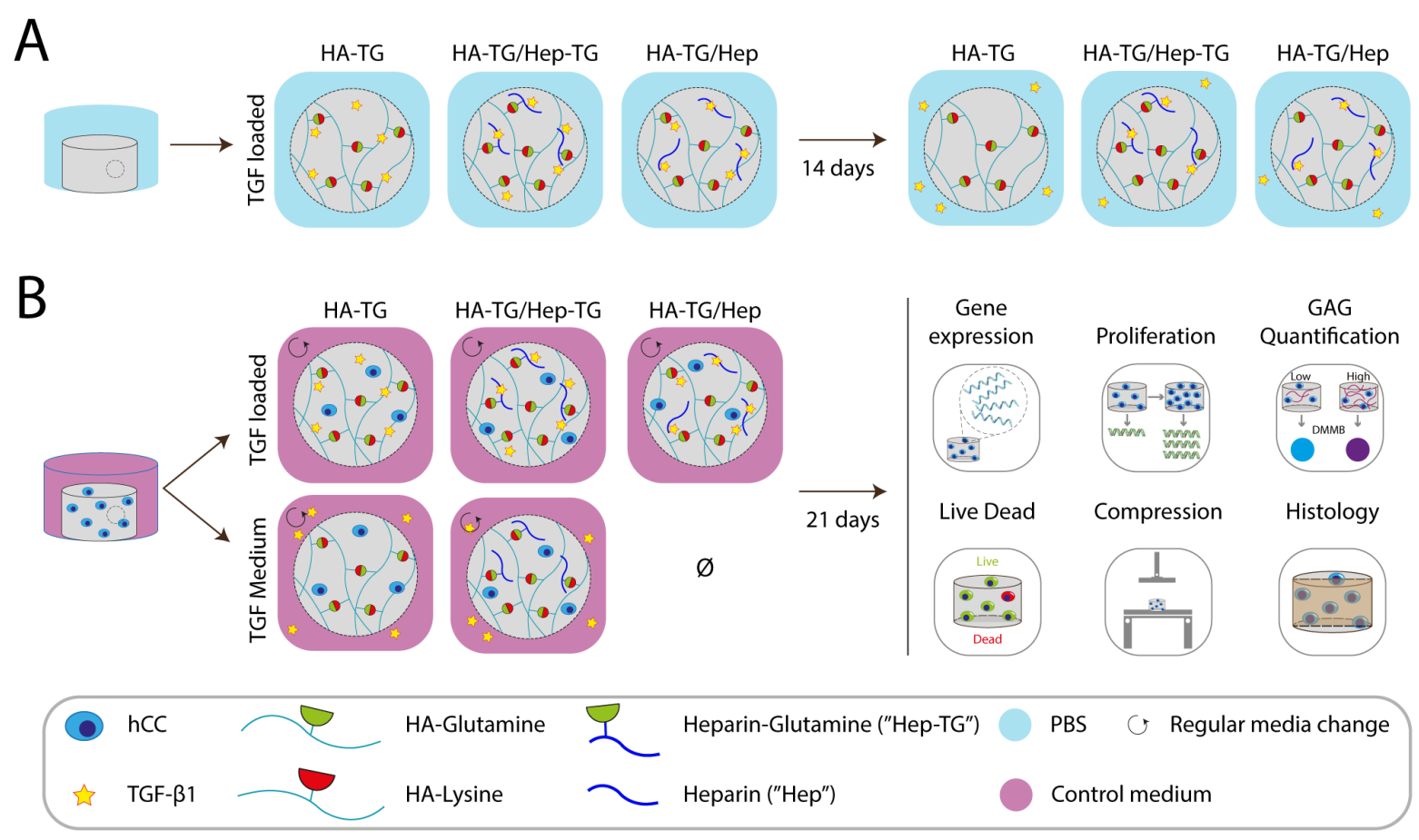

Fig. 1: Schematic of the study design. (A) Acellular constructs were used for the characterization of the gelation behavior with rheology, as well as the release kinetics of heparin and of the initially-loaded TGF- $\beta 1$ (transforming growth factor $\beta 1$ ) after gelation. (B) Human chondroprogenitor cells (hCCs) were encapsulated in either HA-TG, HA-TG with covalently bound heparin (HA-TG/Hep-TG) or HA-TG with non-covalently bound heparin (HA-TG/Hep). A comparison of the two different heparin incorporation methods was conveyed in terms of extracellular matrix production after 21 days. Further experiments comparing TGF- $\beta 1$ administration method (loaded in the gel vs medium-supplemented) did not include HA-TG/Hep. Chondrogenesis was evaluated by characterizing matrix deposition via histology and biochemical assays, measuring chondrogenic genes expression with RT-qPCR as well as quantifying the stiffness with an unconfined compression test. 


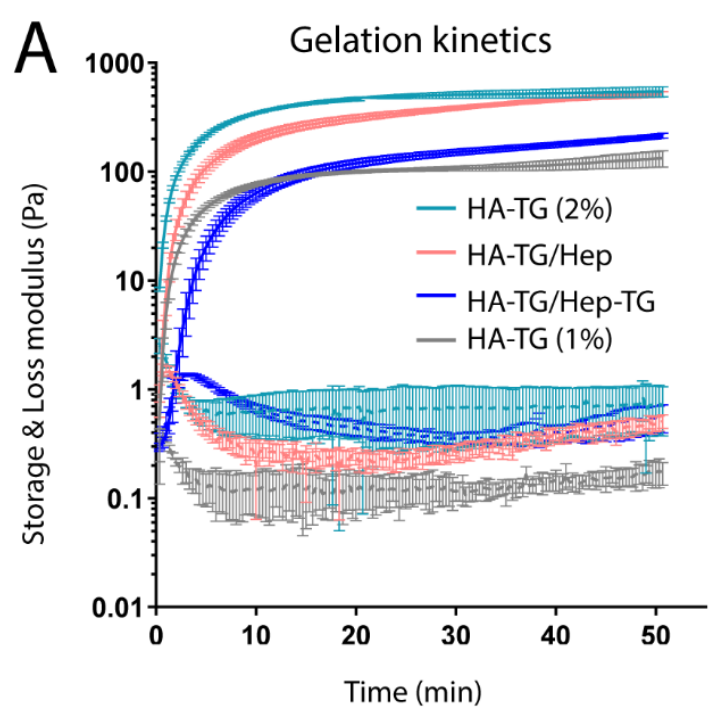

B Heparin release from gels

C

TGF released from gels
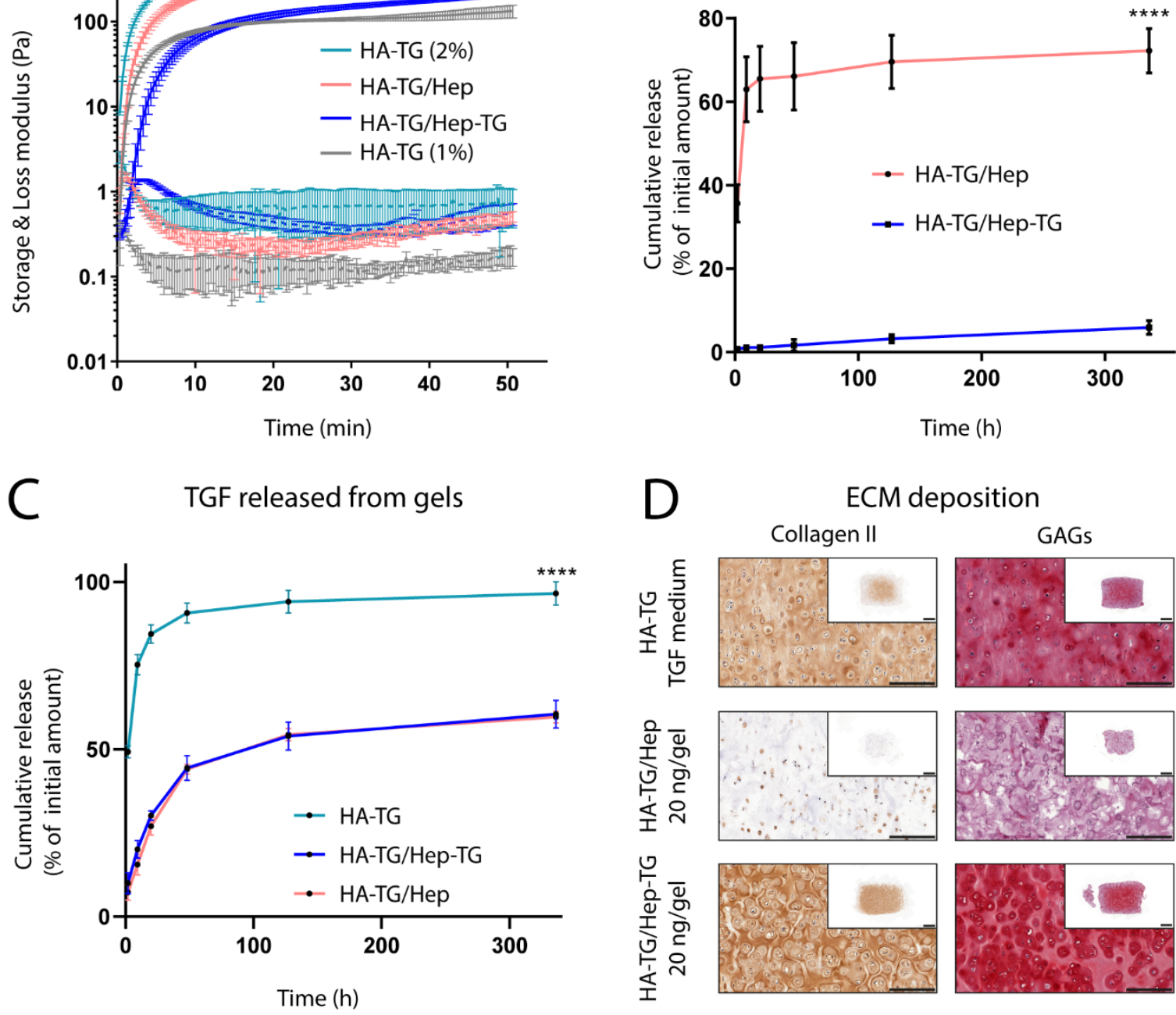

Fig. 2: Only covalent addition of heparin both efficiently retains TGF- $\beta 1$ and promotes cartilaginous matrix deposition. (A) Gelation properties. Gelling curves obtained with a rheometer showed the storage modulus (unbroken lines) and the loss modulus (dotted lines) for two concentrations of HA-TG ( $2 \%$ in light blue and $1 \%$ in grey) and 2 heparin incorporation strategies (unbound in pink and crosslinked in dark blue). $\mathrm{N}=3$ for each condition. (B) Heparin release. Release curves of heparin (pink, $n=3$ ) and Hep-TG (blue, $n=4$ ) from the gels over 2 weeks measured with a DMMB assay. Student $t$ test analysis for the last timepoint. (C) TGF- $\beta 1$ release. Cumulative release curve of TGF- $\beta 1$ from HATG/Hep gels (pink, n=3), HA-TG/Hep-TG gels (dark blue, $n=3$ ) and HA-TG gels (light blue, $n=3$ ) over 2 weeks. Student $t$ test analysis for the last timepoint. (D) ECM deposition by encapsulated hCCs. GAGs and collagen type II production by hCCs encapsulated in either HA-TG with TGF- $\beta 1$ supplemented in the medium (10 ng/ml), HA-TG/Hep or HA-TG/Hep-TG with TGF- $\beta 1$ loaded in the gel at $800 \mathrm{ng} / \mathrm{ml}$ ( $20 \mathrm{ng} / \mathrm{scaffold}), \mathrm{n}=4$ for each condition. Scale bars $=200 \mu \mathrm{m}$ (close-up) and $1 \mathrm{~mm}$ (inset). Histological controls are provided in Fig. B. 
A
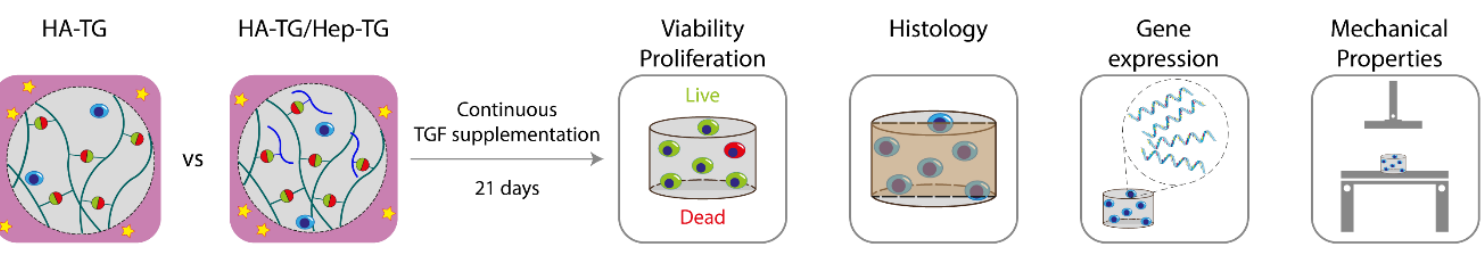

B

(i) Viability
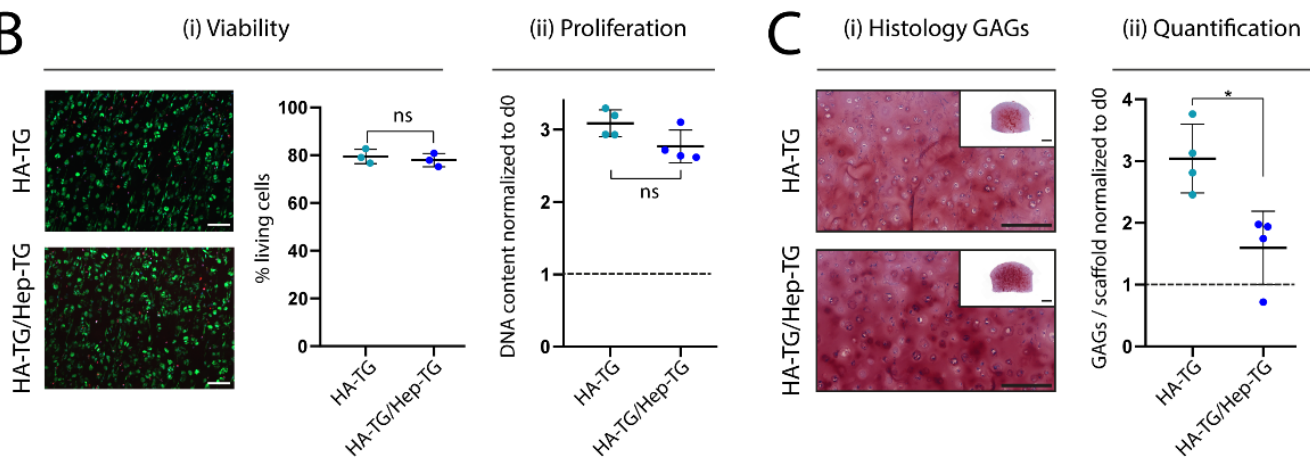

(iii) Gene expression Aggrecan

$\mathrm{D}$

(i) Collagens histology

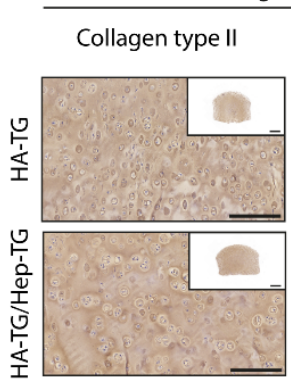
Collagen type I

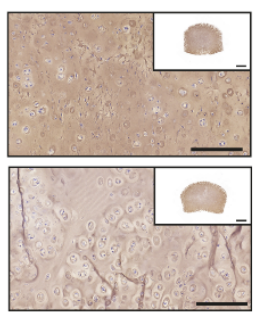

(ii) Collagens gene expression

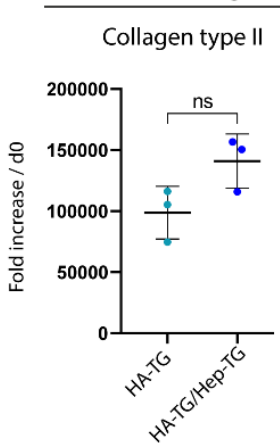

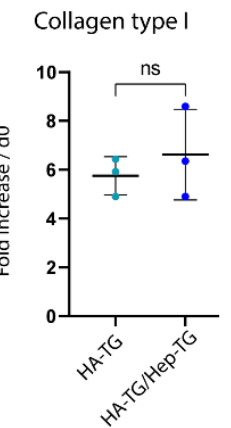

$\mathrm{E}$

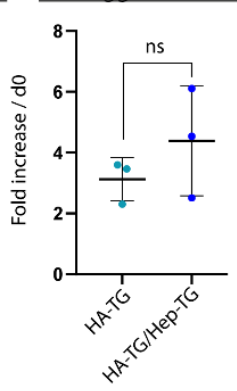

(iii) Mechanical properties

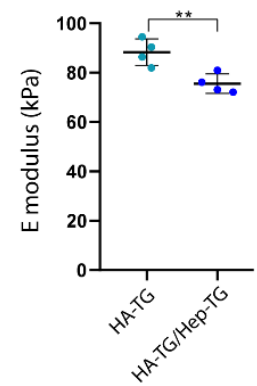

Fig. 3: hCCs chondrogenic potential is not affected upon covalent addition of heparin in HA-TG, when cultured in TGF- $\beta 1$-supplemented medium. (A) Schematic (B) Cellular viability and proliferation

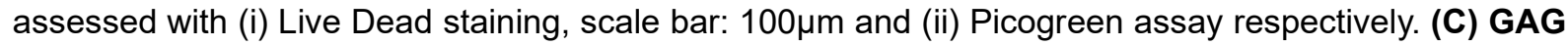
deposition. (i) Safranin O staining ( $n=3$ ), (ii) DMMB quantification in papain-digested gels $(n=4)$ and (iii) gene expression of aggrecan at $\mathrm{d} 21 \quad(\mathrm{n}=3)$.

(D) Collagen type I and II deposition. (i) Immunohistochemical stainings $(n=3)$ and (ii) gene expression at d21 $(n=3)$. (E) Mechanical characterization. Compression modulus after 21 days $(\mathrm{kPa}), \mathrm{n}=4$. For all histology images, scale bar: $200 \mu \mathrm{m}$ (close up) and $1 \mathrm{~mm}$ (insets). 

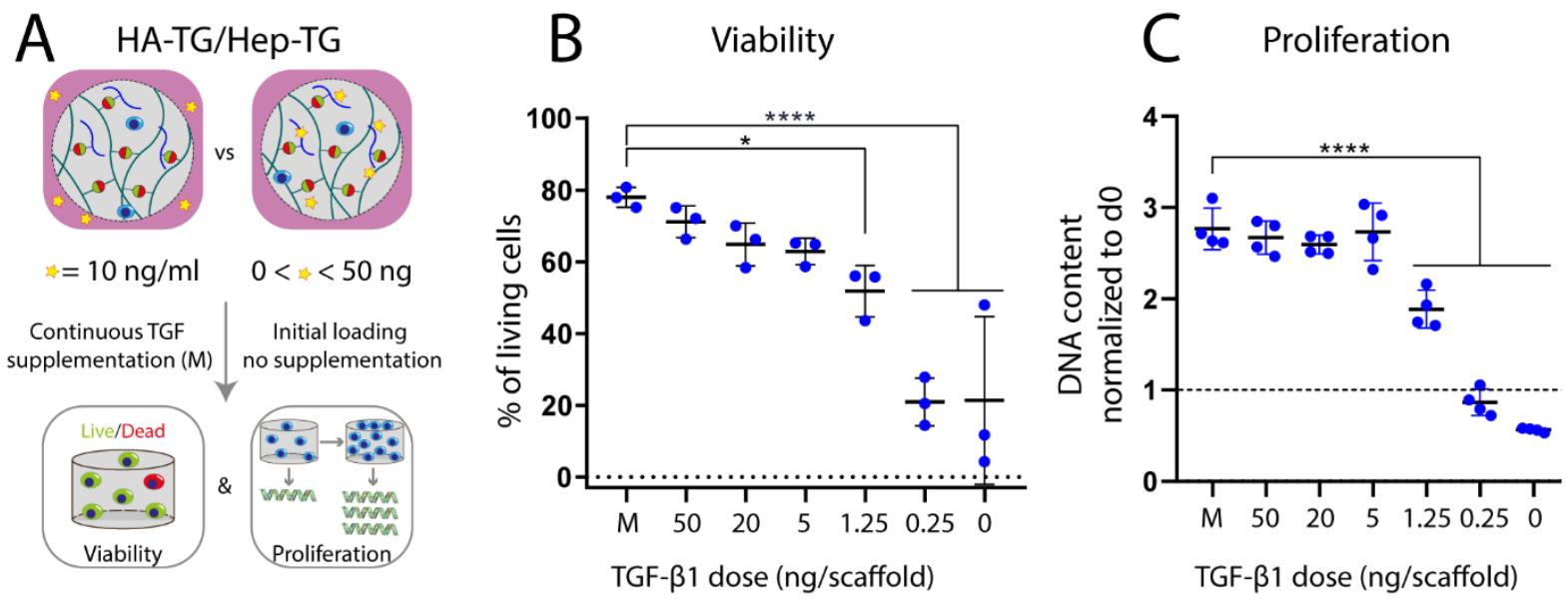

D Medium

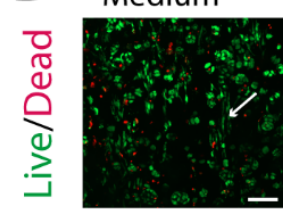

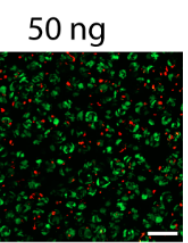
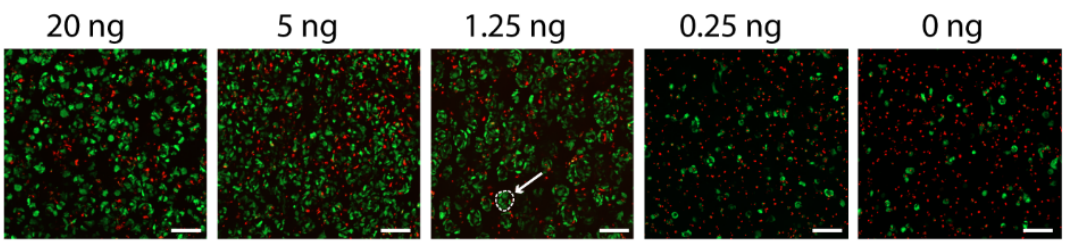

Fig. 4: Initially loaded TGF- $\beta 1$ supports $\mathrm{hCC}$ s viability and proliferation to a similar level as when continuously medium-supplemented, from a dose of $5 \mathrm{ng} / \mathrm{scaffold}$ (A) Schematic (B) Viability quantification. Live dead images quantified with ImageJ $(n=3)$. "M" condition: $10 \mathrm{ng} / \mathrm{ml}$ TGF- $\beta 1$ supplemented in medium). (C) Proliferation. Picogreen assay, $n=4$. ${ }^{* * * *}$ represents $p<0.0001$. (D) Viability assay. Live dead staining of scaffolds after 3 weeks of culture in serum-free medium. $n=3$. Scale bars: $100 \mu \mathrm{m}$. 

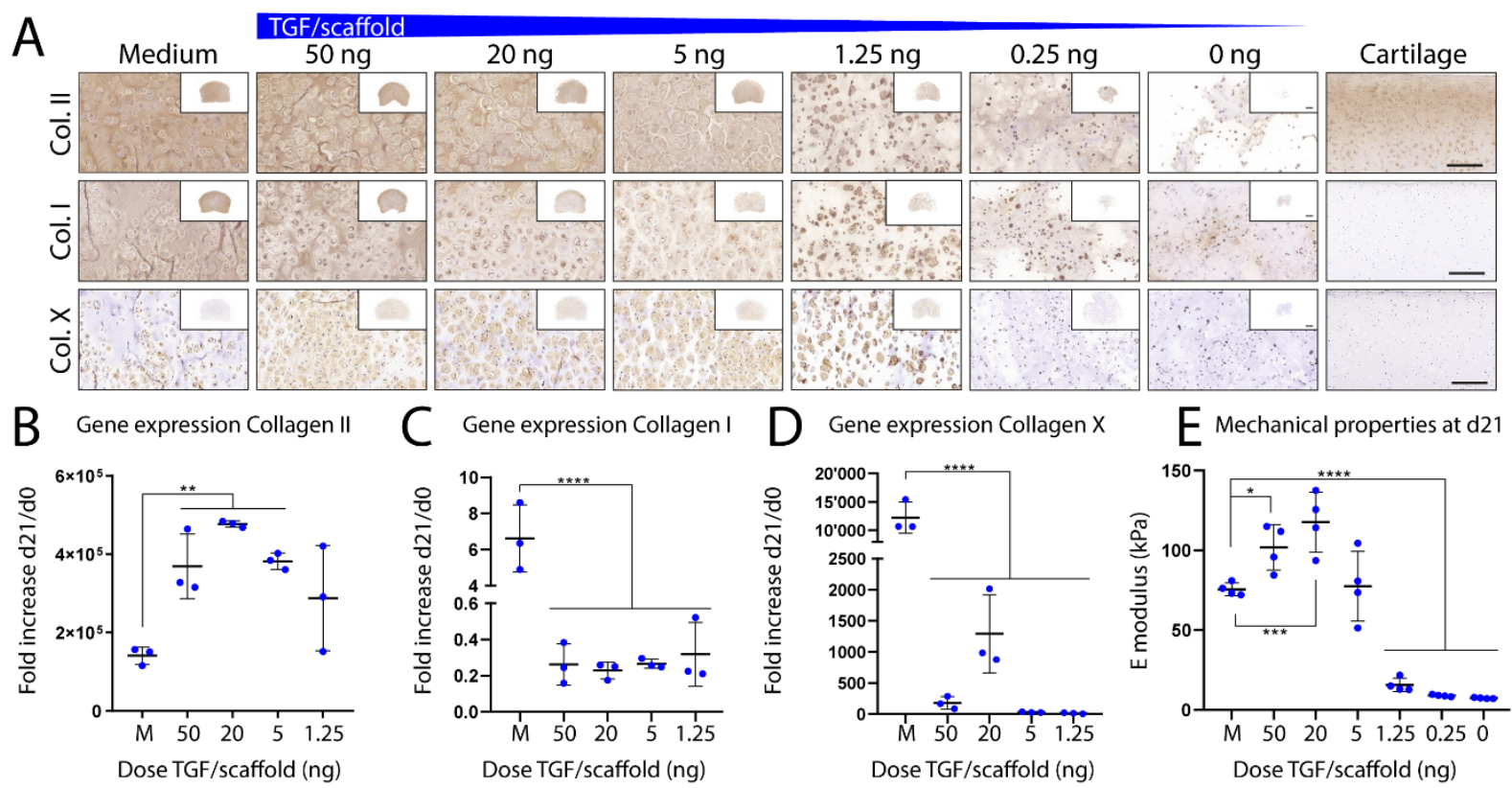

C Gene expression Collagen I

Dene expression Collagen X
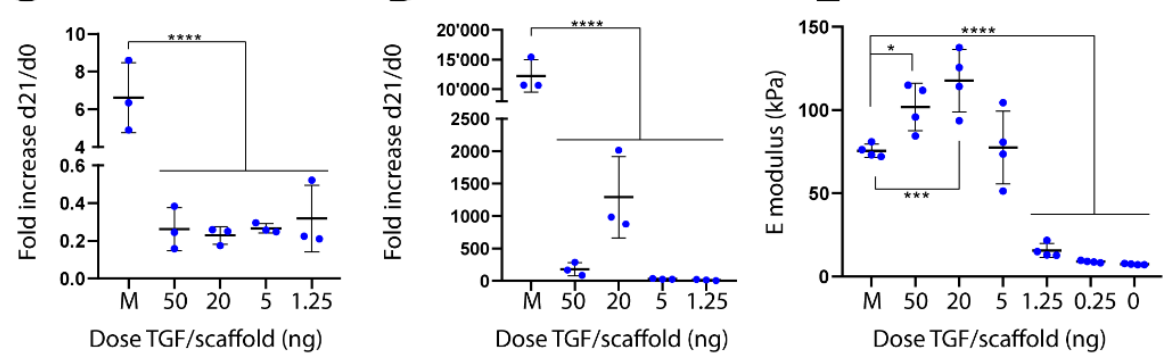

$F_{\text {TGF/scafifold }}$

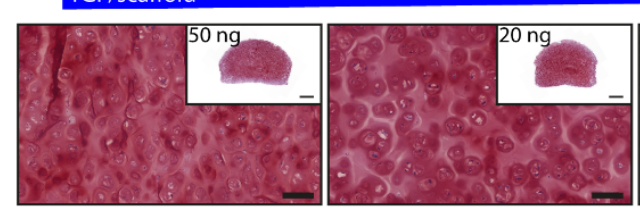

G

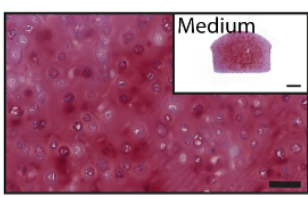

Controls

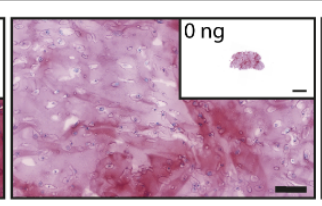

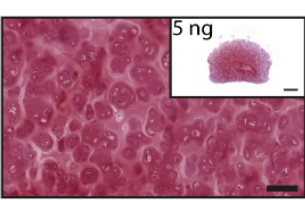

-

$\mathrm{H}$
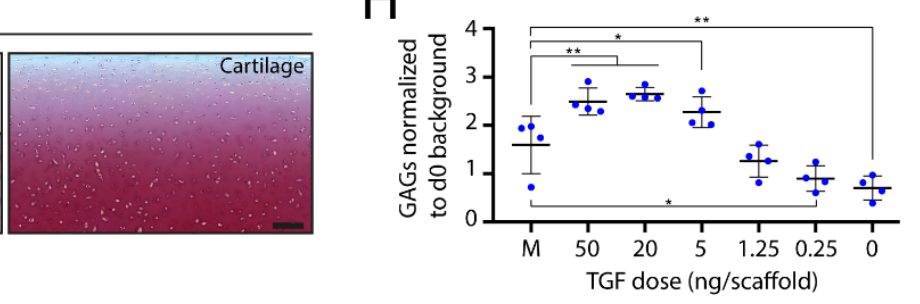

809

810

811

812

813

814

815

816

817

818

819 condition.

Fig. 5: Initially loaded TGF- $\beta 1$ supports homogeneous matrix deposition from a dose of $5 \mathrm{ng} / \mathrm{scaffold}$ with a positive dose response (A) Collagens deposition. Immunohistochemical stainings of Collagen type II, I and X. Scale bars: $200 \mu \mathrm{m}$ (close up) and $1 \mathrm{~mm}$ (inserts). $\mathrm{N}=3$. (B-D) Collagens gene expression as fold increase compared to day 0 for (B) Collagen type II, (C) Collagen type I, (D) Collagen type X. "M" For medium supplementation. $N=3$ for each condition. (E) Stiffness. E moduli (also referred to as compressive moduli) obtained with an unconfined compression test, $n=4$. (F-H) GAGs deposition. Safranin $O$ staining for $(F)$ loading conditions (dose / scaffold indicated on the top left of the insets) and (G) controls. Scale bars: $200 \mu \mathrm{m}$ (close up) and $1 \mathrm{~mm}$ (inserts). N=3. (H) GAGs quantification with DMMB assay on papain-digested gels, normalized to the background measured at day $0 . \mathrm{N}=4$ for each 

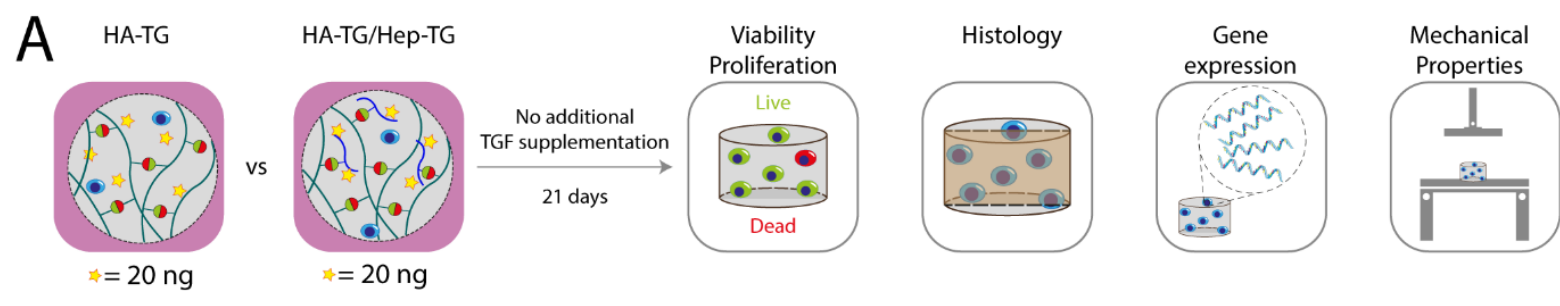

B

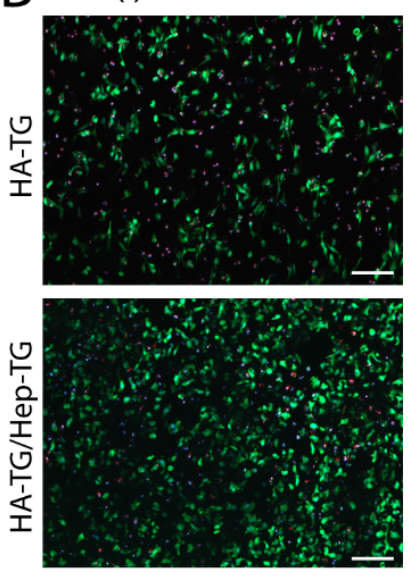

(ii) Viability

(iii) Proliferation

(iv) Mechanical test
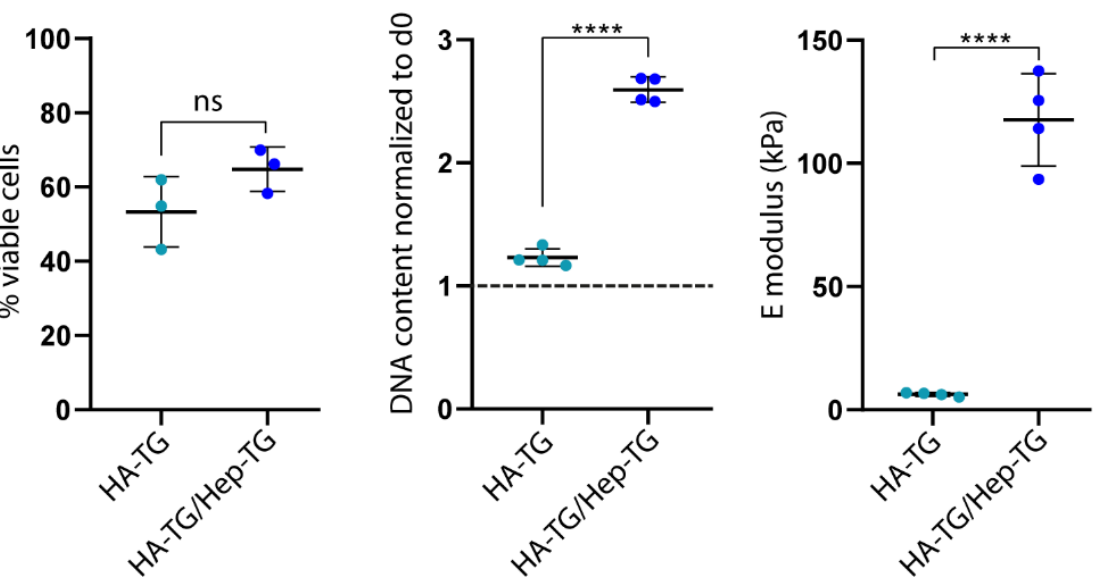

C (i) Histology

(ii) DMMB quantification
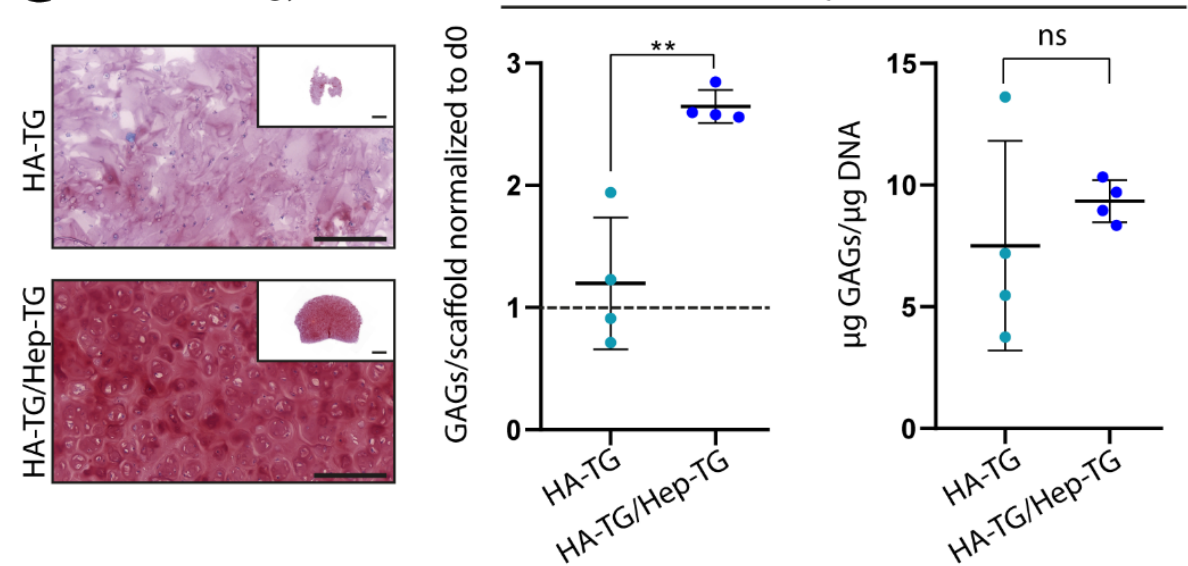

(iii) Gene expression

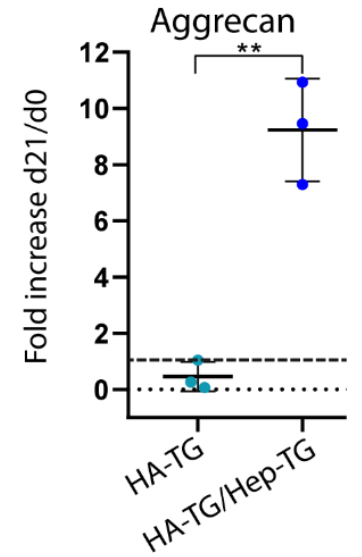

D Collagen type II

(i) Histology
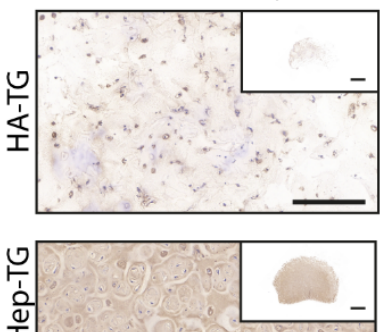

志 (ii) Gene expression

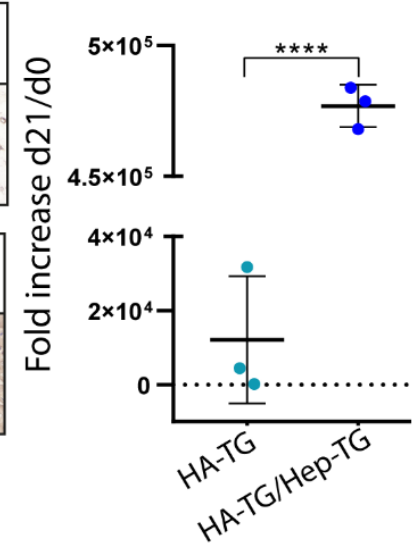

Collagen type I

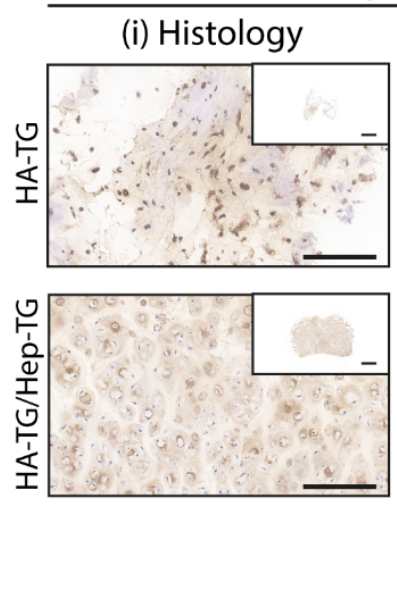

(ii) Gene expression

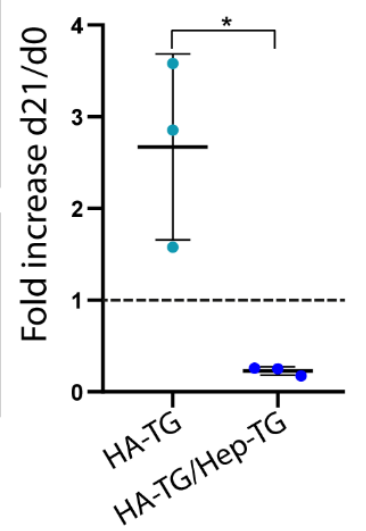

Fig. 6: Sustained release of TGF- $\beta 1$ is required for matrix deposition in vitrolmportance of the sustained release for chondrogenesis. (A) Schematics. (B) Viability, Proliferation and Mechanical properties. (i) Representative Live-dead staining images (scale bar: $100 \mu \mathrm{m}$ ) and (ii) plot of quantified values $(\mathrm{n}=3)$. 
(iii) Proliferation data obtained with a Picogreen assay, $n=4$. (iv) Elastic ( $E$ ) modulus measured with an unconfined compression test, $n=4$. (C) GAGs deposition. (i) Representative images of Safranin $O$ stainings ( $n=3$ ) and (ii) plotted values of quantified amounts of GAGs deposited, either normalized to the background at d0 (left) or to the amount of DNA (right), $n=4$. (iii) Plotted value of Aggrecan gene expression fold increase compared to d0. (D) Collagens deposition. Collagen type I and II representative immunohistological stainings (i) and plotted relative amount of gene expression relative to d0 (ii). For all histological images, scale bar: $200 \mu \mathrm{m}$ (close up) and $1 \mathrm{~mm}$ (inserts).

\section{Supplementary figures}
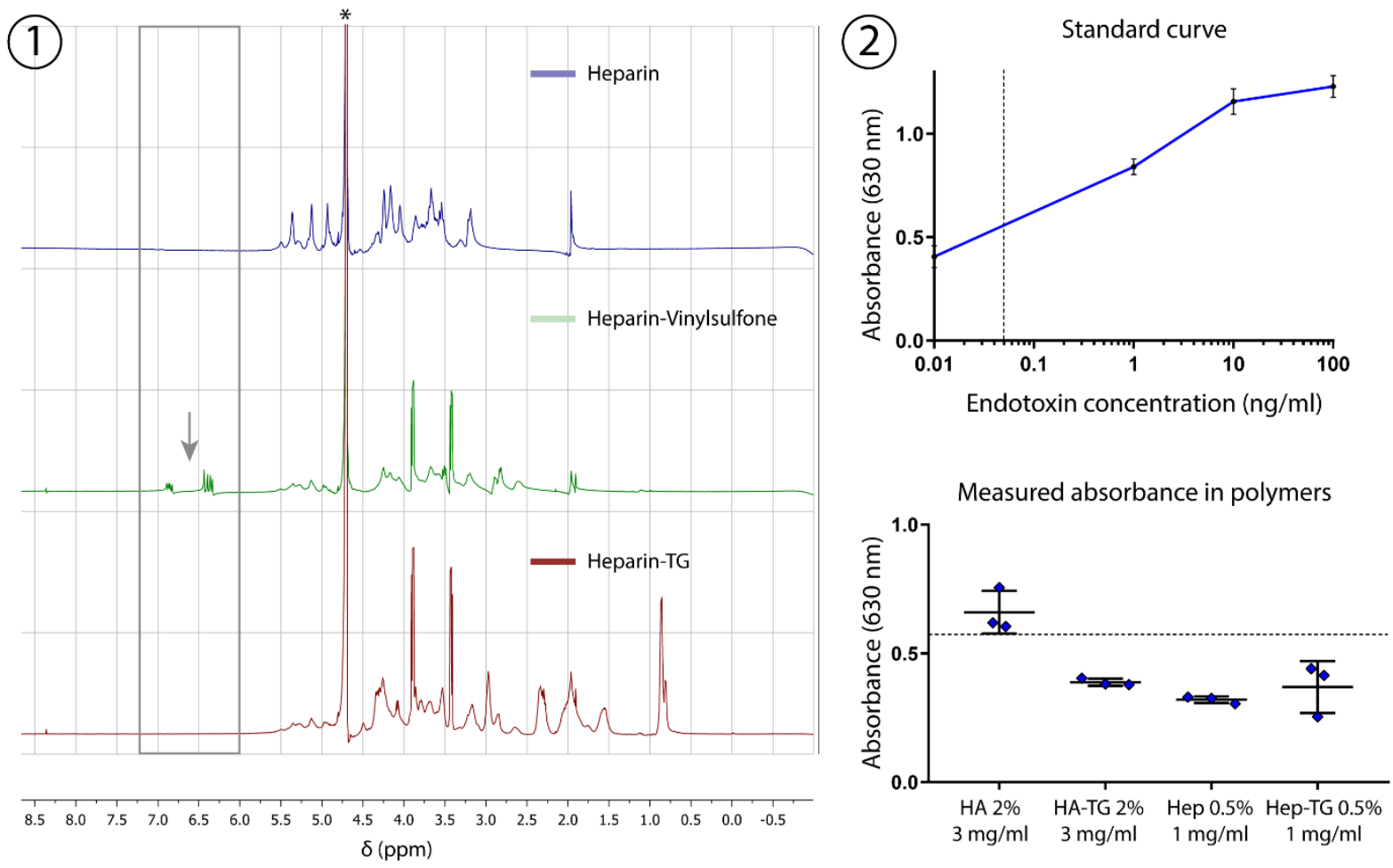

Fig. A: NMR confirms the presence of vinylsulfone peaks and QUANTI-blue assay validates the absence of endotoxins from the polymer solutions (1) Validation of two major steps of Hep-TG synthesis. Proton-NMR of the starting heparin (blue), the intermediate vinylsulfonated heparin (green) and the final heparin-TG (red). The location of the peaks corresponding to the vinylsufone moieties is squared in the 3 stacked spectra and pointed out in the middle spectrum with an arrow. (2) Validation of the absence of endotoxin in starting / final products. Material from animal origin bear the risk of containing endotoxins, whose amounts are regulated by ISO guidelines. Quantification of endotoxin performed with a QUANTI-Blue assay. Standard curve (top) and measured values for starting and final products (bottom) are show as separate graphs, as most of the values found were under the detection limit. Of note, the concentrations were chosen based on the concentration to which the cells are exposed to, but lowered to an amount that is not leading to a viscous solution for the HA. The limit of $0.57 \mathrm{~nm}$ of absorbance corresponds to an endotoxin concentration of $0.05 \mathrm{ng} / \mathrm{ml}$ (or $0.5 \mathrm{EU} / \mathrm{ml}$ considering the acknowledged conversion of $10 \mathrm{EU} / \mathrm{ml}=1 \mathrm{ng} / \mathrm{ml}$ ), which is the limit fixed by the FDA for medical devices. 


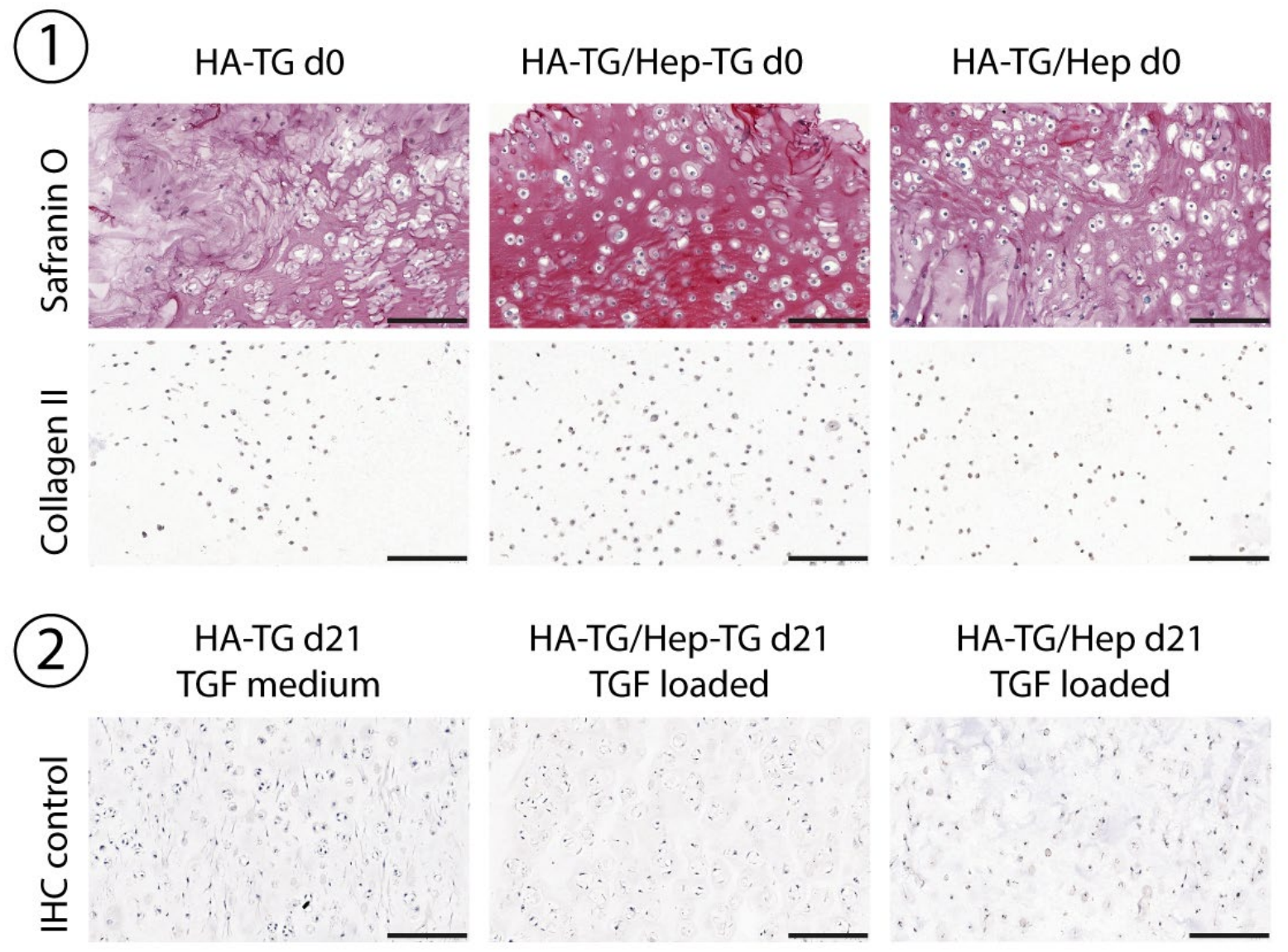

Fig. B: Histological controls (1) Day 0 background. Gels made on the day of the experiment were directly fixed and processed for paraffin embedding (due to the high water content of the gels and the dehydration steps of paraffin embedding, an important shrinkage can be observed, leading to potential increase of staining intensity due to the wrinkling). Safranin $O$ seems to have an increased intensity in HA-TG/Hep-TG compared to HA-TG, despite the low amount present in the gel $(0.1 \%)$ and although this increased intensity is visible to a lower extent in HA-TG/Hep. Collagen type II staining is positive in the cells but not in the scaffold. (2) Day 21 background for immunohistochemistry (IHC). Representative images obtained in absence of primary antibody (the rest of the protocol being identical). 
(1) Safranin O staining

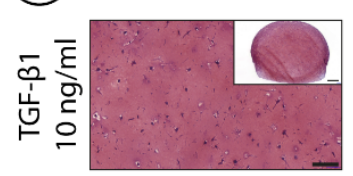

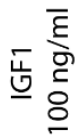

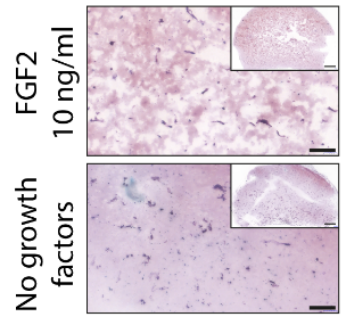

(2) TGF- $\beta 3$ release in the supernatant

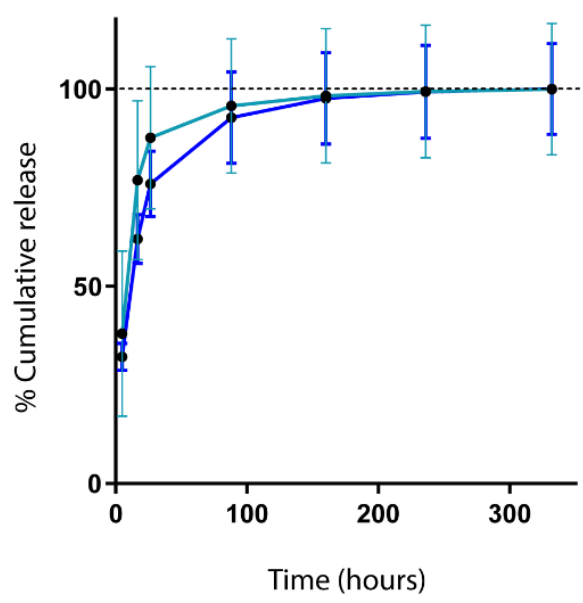

(3) TGF- $\beta 1$ release in the supernatant

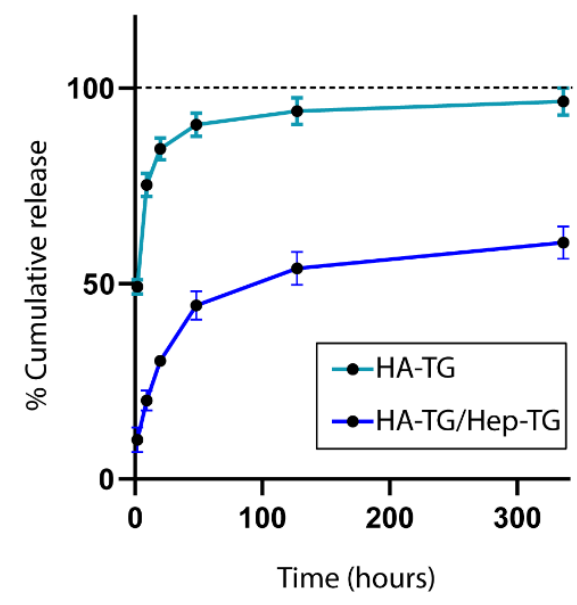

Fig. C: IGF1, FGF2 and TGF-b3 fail to either promote ECM deposition when supplemented in the cell culture media or bind to bind to heparin in HA-TG/Hep-TG (1) Preliminary screen of different GFs widely used for cartilage tissue engineering. Safranin $O$ staining of $5 \mu \mathrm{m}$-thick cryosections (samples were soaked in $10 \%$ sucrose for 1 hour and $30 \%$ sucrose overnight, infiltrated at room temperature in O.C.T (Tissue-Tek) and snapfrozen, then cut at a cryostat CryoStar NX70 (Thermo Scientific). Scale bars: $100 \mu \mathrm{m}$ (close up) and $500 \mu \mathrm{m}$ (inserts). $\mathrm{N}=2$. (2) Release kinetics of TGF- $\beta 3$, from HA-TG (light blue) and HA-TG/Hep-TG (dark blue). (3) Release kinetics of TGF- $\beta 1$, from HA-TG (light blue) and HA-TG/Hep-TG (dark blue). For (2) and (3), the curves represent the cumulative percentage of the initially loaded amount of TGF- $\beta$, released in the supernatant. 

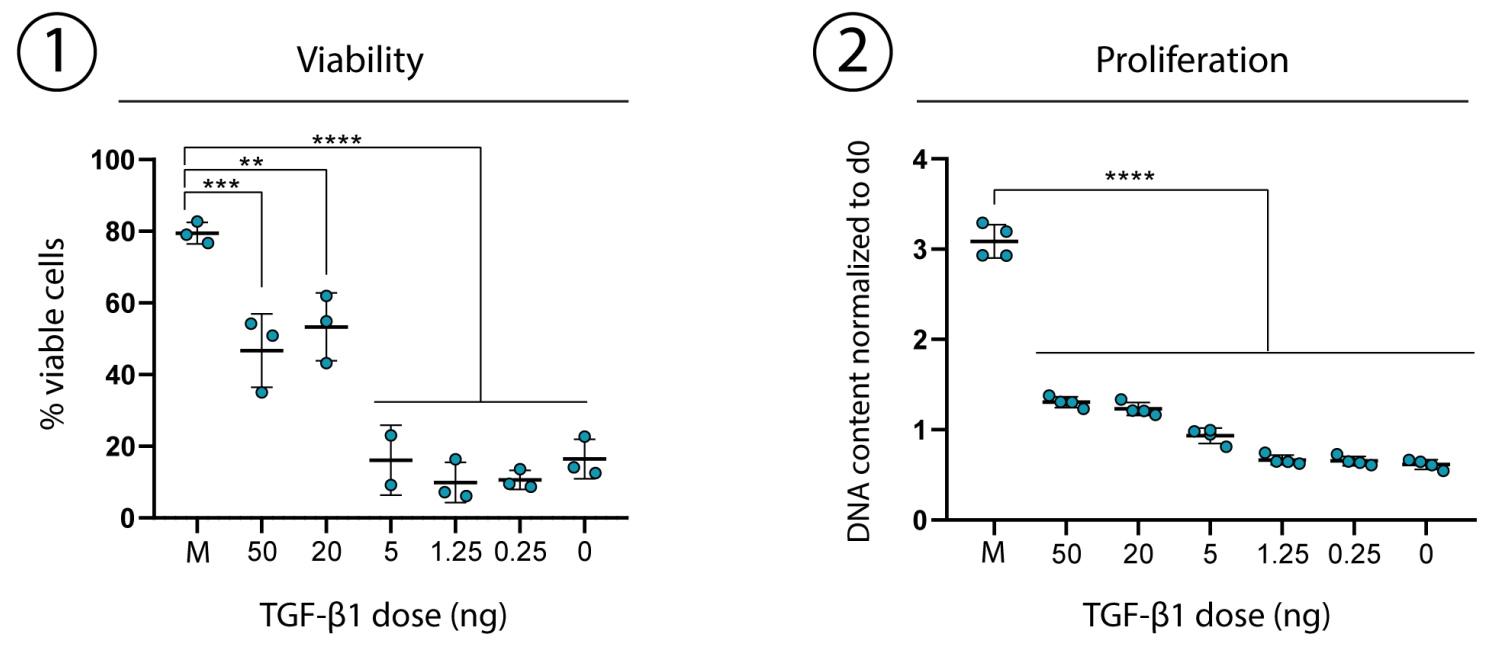

Gene expression
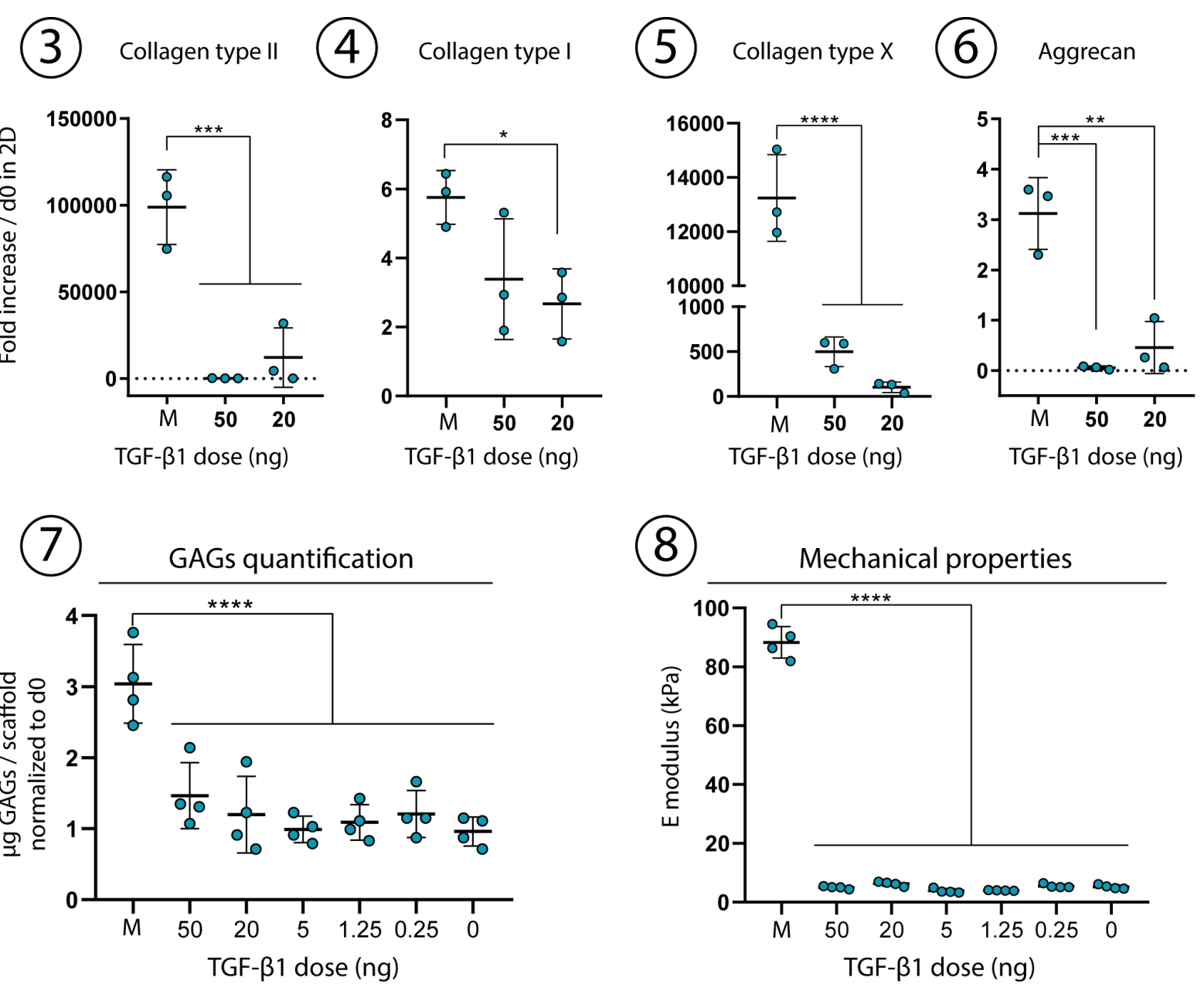

Fig. D: TGF- $\beta 1$ burst release does not promote chondrogenesis at any of the tested doses (1) Viability. Plot of Live dead images quantification with Image J $(n=3)$. (2) Proliferation. Picogreen assay, $n=4$. (36) Collagens gene expression as fold increase compared to day 0 for (3) Collagen type II, (4) Collagen type I, (5) Collagen type X and (6) Aggrecan. N=3 for each condition. (7) Quantification of GAGs in scaffolds with DMMB assay. $\mathrm{N}=4$ for each condition. (8) Mechanical properties. $E$ modulus measured with an unconfined compression test, $n=4$. For all plots, "M" indicates the condition with TGF medium supplementation. 